\title{
Microhistorias de la Prehistoria Reciente en el interior de la Península Ibérica
}

\author{
Microhistories of later prehistoric Central Iberia
}

\author{
Antonio Blanco-González ${ }^{\mathrm{a}}$
}

\section{RESUMEN}

Se presentan los presupuestos y resultados de un proyecto de investigación orientado a caracterizar los ciclos formativos del registro arqueológico en la Prehistoria Reciente meseteña. Frente a las lecturas generalistas predominantes se propone una aproximación inductiva y particularista, de microescala. El análisis, diseñado como un estudio de caso múltiple, se aplicó a las colecciones cerámicas de ocho sitios (asentamientos, campos de hoyos, monumentos) cubriendo del Neolítico Antiguo al Bronce Final (c. 5500-1100 AC). 10.800 fragmentos de variados contextos (pozos, foso, tumba, túmulos, cabaña) fueron evaluados conforme a variables tafonómicas (tamaño, erosión, vasijas representadas) informativas de sus dinámicas de descarte y abandono. Una lectura diacrónica y comparativa permite apreciar prácticas sociales transculturales (rotura, circulación y ocultación de sustancias). Se reconocen dos tipos de ciclos antropogénicos: a) una mayoría de efectos resultantes de procesos muy heterogéneos, implicando la manipulación despreocupada de desechos; y b) una minoría de productos planeados, más fácilmente reconocibles. from assorted anthropogenic features (gullies, ditch, pits, tumuli, hut) were assessed according to a series of taphonomic variables (size, erosion, parent vessels) informing abandonment dynamics. A diachronic and comparative account drawing on these highly-detailed observations allows better ascertaining cross-cultural social practices (deliberate fragmentation, circulation and deposition of substances) and their currency. The results mostly comprise unintended material effects from heterogeneous processes dealing with everyday refuse management and some exceptional deliberate end products, more easily identified.

Palabras clave: Inducción; Paradigma indiciario; Microhistoria; Investigación con estudio de casos; Tafonomía cerámica; Prehistoria Reciente; Meseta peninsular.

Key words: Induction; Conjectural paradigm; Microhistory; Case-study research; Ceramic taphonomy; Later Prehistory; Iberian Central Meseta.

\section{INTRODUCCIÓN}

Entre 1990 y 2010, la investigación arqueológica en la Península Ibérica ha avanzado enormemente gracias a estrategias académicas y preventivas, que ofrecen resultados de resolución y escala muy desiguales y difícilmente compatibles. Contamos con unas pocas ventanas abiertas a realidades locales desgranadas minuciosamente, enmarcadas por extensas zonas conocidas de forma más selectiva e imprecisa. Sobre esta documentación, distintas
This paper presents the intellectual framework and
outcomes of a research project designed to characterize
the formation cycles of the archaeological record in later
prehistoric Iberian Meseta or Central Plateau. Contrary
to mainstream generalist discourses and grand histories,
an inductive, particularistic and microscale approach is
advocated. A multiple-case study was conducted, based on
ceramic assemblages from eight sites (settlements, pit sites,
monuments) ranging from the Early Neolithic to the Late
Bronze Age (c. 5500-1100 BC). A total of 10,800 potsherds

a Dpto. de Prehistoria, Arqueología, Antropología Social y Ciencias y Técnicas Historiográficas. Facultad de Filosofía y Letras. Plaza del Campus s/n. 47011 Valladolid. Correo e: ablancoglez@gmail.com

Recibido 18-IX-2015; aceptado 3-XII-2015. 
formas de hacer arqueología en la Península Ibérica han adoptado, casi unánimemente, un enfoque generalista. Así, las aproximaciones deterministas, materialistas y procesuales han ido esbozando en prácticamente todas las regiones las grandes tendencias de evolución tecnológica, sociopolítica y cultural durante la Prehistoria Reciente. Sin embargo, el avance en otros frentes, desde enfoques alternativos y operando a distinto nivel de detalle, comienza a advertir cierta desconexión entre datos e interpretaciones (e.g. Montón-Subías 2010; Weiss-Krejci 2012; Aranda et al. 2015: xxiii). Se acumulan las contradicciones entre lo que esos modelos hipotético-deductivos prevén y lo que en realidad encontramos (Barroso et al. 2014: 119). La inferencia arqueológica no siempre ha reunido las necesarias garantías, y conviene abordar el registro arqueológico desde otros frentes, reconociendo las limitaciones de nuestros instrumentos de observación y conceptos interpretativos.

En este artículo se exponen el planteamiento y los resultados de un proyecto de investigación dedicado a revisar tales cuestiones en la Prehistoria Reciente de la Meseta (c. 5500-1100 cal AC). El epígrafe 2 esboza el marco teórico y metodológico: el problema abordado es nuestra dificultad para generar conocimiento a partir de unos testimonios prehistóricos muy complejos y poco elocuentes. Se presenta el enfoque de microescala adoptado; frente al predominio deductivo-generalista y las grandes narrativas, aquí se propone inferir inductivamente, es decir, proceder desde lo particular escrutado minuciosamente para caracterizar unos ciclos formativos (Jiménez Jáimez 2008) desconocidos. Se define la estrategia de muestreo seguida como un estudio de caso múltiple (Yin 2003) y se detalla el protocolo de tafonomía cerámica aplicado. El apartado 3 presenta una exploración diacrónica y comparativa de esas observaciones, entendidas como microhistorias (Ginzburg 2013; Magnússon y Szijártó 2013).

\section{MARCO TEÓRICO Y METODOLÓGICO}

\subsection{Planteamiento del problema}

Apenas comprendemos a qué responden las acumulaciones de desechos encontradas. Reconocemos intuitivamente los restos de actividades cotidianas (desperdicios de comida, cenizales, utensilios y subproductos de tareas, etc.), pero identificar áreas de actividad o 'niveles de ocupación' no es sencillo ni obvio (Matthews 1993). En la Prehistoria Reciente europea los desperdicios domésticos fueron a menudo trasegados (Rídký et al. 2014); son materiales secundarios o terciarios (Butzer 2007: 110-111) o responden a celebraciones sociales -depósitos de inauguración o clausura de asentamientos- distintas al discurrir cotidiano (Waddington 2014: 90-92). Identificar una estructura como vivienda no garantiza que su relleno resulte de actividades domésticas allí desarrolladas (Hayden y Cannon 1983). Al interpretar el relleno de viviendas, su sedimentación natural progresiva (Butzer 2007: 120-131) o catastrófica y súbita-como en Pompeya (Schiffer 1985; Jiménez Jáimez 2008: 132-133)- han sido los referentes más asumidos, pero apenas demostrados. Como veremos, la más reciente investigación peninsular minimiza la contribución de los factores naturales en unos contextos prehistóricos primordialmente antropogénicos. Un ‘depósito pompeyano' (Schiffer 1985) contendría desechos de facto no descartados, es decir, enseres aprovechables atrapados por el desplome de paredes y techo (Tab. 1). Tal supuesto se reconoce en el violento incendio de Genó (Lérida) (Maya et al. 1998: 171) o el derrumbe de la fase IIIA de Peñalosa (Jaén) (Contreras Cortés et al. 2000: 69-70). Sin embargo, la experiencia etnohistórica y la arqueología de campo muestran que tal circunstancia fue excepcional y que podemos encontrar otras muchas situaciones, apenas consideradas: a) los suelos de las estancias frecuentemente se limpiaban y sólo quedaron microdesechos (VVAA 2003; Jiménez Jáimez 2008: 129); b) los cúmulos de detritos que colmatan algunas viviendas pudieron arrojarse tras su abandono (Cameron y Tomka 1993; LaMotta y Schiffer 1999: 22-24); y c) el ámbito doméstico a menudo acogió restos de ceremonias $\mathrm{u}$ ofrendas, tanto fundacionales como terminales (Walker 1995; Waddington 2014).

Tampoco es prudente etiquetar a priori aquellos materiales no domésticos que destacan por su rareza, completitud o carácter deliberado (Robb 2007: 74). Cualquier resto humano no es automáticamente funerario, es decir, resultado del tratamiento escatológico de un recién difunto (Leclerc 1990: 14-16); existen muchas otras costumbres mortuorias (Thomas 2000: 655-666; Liesau et al.

Trab. Prehist., 73, N. ${ }^{\circ}$ 1, enero-junio 2016, pp. 47-67, ISSN: 0082-5638

doi: $10.3989 /$ tp. 2016.12163 


\begin{tabular}{|c|c|c|c|}
\hline Variables & Depósito 'pompeyano’ & Producto deliberado & Efecto fortuito \\
\hline Tipo de hallazgo & $\begin{array}{c}\text { Desecho de facto } \\
\text { (Schiffer 1987) = cosas } \\
\text { aún usables abandonadas } \\
\text { prematuramente, sin } \\
\text { experimentar descarte } \\
\text { convencional. }\end{array}$ & $\begin{array}{l}\text { Depósito = elementos } \\
\text { abandonados con } \\
\text { formalidad, según } \\
\text { preceptos culturales } \\
\text { distintos a los que rigen } \\
\text { en el descarte ordinario } \\
\text { de desechos anodinos. }\end{array}$ & $\begin{array}{c}\text { Material culture } \\
\text { patterning (Garrow } \\
\text { 2012) = agregado } \\
\text { acumulativo y azaroso de } \\
\text { ítems prosaicos, efecto } \\
\text { despreocupado (incluso } \\
\text { inadvertido) fruto de } \\
\text { costumbres habituales. }\end{array}$ \\
\hline $\begin{array}{l}\text { Situación dentro } \\
\text { del ciclo formativo } \\
\text { y temporalidad }\end{array}$ & $\begin{array}{l}\text { Conjunto 'sistémico' en } \\
\text { uso (Schiffer 1987), en } \\
\text { posición primaria (in } \\
\text { situ); sus elementos son } \\
\text { coetáneos y responden } \\
\text { a temporalidades breves } \\
\text { (sincronicidad intensa). }\end{array}$ & $\begin{array}{c}\text { Ítems en posición } \\
\text { primaria o secundaria (= } \\
\text { abandonados, recuperados } \\
\text { y depositados). Varias } \\
\text { temporalidades, pueden } \\
\text { estar temporalmente } \\
\text { promediados (time- } \\
\text { averaged). }\end{array}$ & $\begin{array}{c}\text { Residuos secundarios o } \\
\text { terciarios } \\
\text { (= depositados, } \\
\text { recuperados y } \\
\text { redepositados). } \\
\text { Diversas temporalidades } \\
\text { (sincronicidad } \\
\text { lábil). Palimpsestos } \\
\text { temporalmente } \\
\text { promediados. }\end{array}$ \\
\hline Factores formativos & $\begin{array}{l}\text { Abandono súbito } \\
\text { e imprevisto por } \\
\text { causas naturales (p.ej. } \\
\text { inundación, terremoto, } \\
\text { incendio, deslave) o por } \\
\text { episodios antrópicos } \\
\text { repentinos (destrucción } \\
\text { violenta, derribo). }\end{array}$ & $\begin{array}{l}\text { Actividades terminales, } \\
\text { bien según las normas } \\
\text { corrientes (la mayoría de } \\
\text { los depósitos formales) } \\
\text { o bien según preceptos } \\
\text { de ocasión (incluso } \\
\text { improvisados) bajo } \\
\text { circunstancias anómalas } \\
\text { (p.ej. abandonos } \\
\text { o enterramientos } \\
\text { excepcionales). }\end{array}$ & $\begin{array}{l}\text { Múltiples combinaciones } \\
\text { de factores naturales y } \\
\text { antrópicos. Los procesos } \\
\text { de adición y merma } \\
\text { pudieron entremezclarse, } \\
\text { resultando en la } \\
\text { compleja configuración } \\
\text { de la fracción material } \\
\text { superviviente. }\end{array}$ \\
\hline $\begin{array}{l}\text { Localización } \\
\text { y relaciones espaciales }\end{array}$ & $\begin{array}{l}\text { Los ítems conservan } \\
\text { su ordenación espacial } \\
\text { original. Los fragmentos } \\
\text { de una misma vasija } \\
\text { yacen próximos. }\end{array}$ & $\begin{array}{l}\text { Los restos retienen los } \\
\text { patrones espaciales del } \\
\text { contexto original. Las } \\
\text { partes de un mismo } \\
\text { objeto colocado entero } \\
\text { yacen próximas. }\end{array}$ & $\begin{array}{l}\text { Patrón espacial original } \\
\text { severamente deformado } \\
\text { e irremediablemente } \\
\text { perdido, por lo que las } \\
\text { actividades primarias } \\
\text { (si las hubo) apenas } \\
\text { pueden ser rastreadas. }\end{array}$ \\
\hline $\begin{array}{c}\text { Completitud y pautas } \\
\text { de rotura }\end{array}$ & $\begin{array}{c}\text { Mayoritariamente } \\
\text { objetos rotos, pero } \\
\text { reconstruibles completos: } \\
\text { vasijas sin lagunas } \\
\text { (excepto pequeñas partes } \\
\text { destruidas o extraviadas } \\
\text { en la excavación). Rotura } \\
\text { natural, accidental } \\
\text { e in situ. }\end{array}$ & $\begin{array}{l}\text { Contiene tanto objetos } \\
\text { enteros como parciales. } \\
\text { Rotura natural y gradual } \\
\text { de vasija (por peso } \\
\text { sorportado): las partes } \\
\text { yacen próximas y punto } \\
\text { de impacto ausente. } \\
\text { Rotura deliberada de } \\
\text { vasija (arrojada): punto } \\
\text { de impacto y fracturas de } \\
\text { patrón radial. }\end{array}$ & $\begin{array}{l}\text { Principalmente objetos } \\
\text { fragmentarios, rotos en } \\
\text { otro lugar. Puede haber } \\
\text { artefactos completos, } \\
\text { descartados } \\
\text { y abandonados. }\end{array}$ \\
\hline
\end{tabular}

Tab. 1 [1] Escenarios deposicionales arquetípicos y valores tafonómicos asociados. 


\begin{tabular}{|c|c|c|c|}
\hline Variables & Depósito 'pompeyano' & Producto deliberado & Efecto fortuito \\
\hline $\begin{array}{l}\text { Conservación } \\
\text { y tafonomía }\end{array}$ & $\begin{array}{l}\text { Meteorización nimia o } \\
\text { nula, fracturas de aspecto } \\
\text { fresco. Los ítems de un } \\
\text { mismo conjunto exhiben } \\
\text { alteraciones uniformes } \\
\text { (p.ej. deformación } \\
\text { térmica u hollín si } \\
\text { sufrieron un incendio). }\end{array}$ & $\begin{array}{l}\text { Según la temporalidad } \\
\text { de los despojos cuando } \\
\text { fueron incluidos en el } \\
\text { contexto. Aquellos restos } \\
\text { sometidos a similar } \\
\text { degradación mostrarán } \\
\text { afecciones homogéneas. }\end{array}$ & $\begin{array}{l}\text { Según la temporalidad de } \\
\text { los restos cuando entraron } \\
\text { en el contexto. Múltiples } \\
\text { alteraciones heterogéneas } \\
\text { pudieron afectar a los } \\
\text { ítems de diversa manera. }\end{array}$ \\
\hline Tamaño de los restos & $\begin{array}{l}\text { Fragmentos de una } \\
\text { misma vasija tienden a } \\
\text { ser homogéneos. Entre la } \\
\text { vajilla común predomina } \\
\text { el tamaño mediano- } \\
\text { grande. }\end{array}$ & $\begin{array}{c}\text { Fragmentos de una } \\
\text { misma vasija tienden a } \\
\text { ser homogéneos y de talla } \\
\text { mediana-grande (excepto } \\
\text { si hay punto de impacto } \\
=\text { materia desaparecida y } \\
\text { orla de pedazos menores). }\end{array}$ & $\begin{array}{l}\text { Gran heterogeneidad, } \\
\text { incluso entre fragmentos } \\
\text { de la misma vasija, } \\
\text { debido al desgaste pos- } \\
\text { rotura. Los tamaños } \\
\text { pequeños pueden } \\
\text { predominar. }\end{array}$ \\
\hline Restos que casan entre sí & $\begin{array}{l}\text { Alta frecuencia de } \\
\text { fragmentos concertantes. }\end{array}$ & $\begin{array}{l}\text { Variable según el grado } \\
\text { de completitud del objeto } \\
\text { cuando fue depositado. }\end{array}$ & $\begin{array}{l}\text { Reducido número de } \\
\text { fragmentos que casan. }\end{array}$ \\
\hline $\begin{array}{l}\text { Fragmentos 'huérfanos' } \\
\text { (sin remontaje local) }\end{array}$ & $\begin{array}{c}\text { En número bajo o } \\
\text { nulo, salvo posibles } \\
\text { microdesechos } \\
\text { remanentes en el suelo, } \\
\text { paredes o techo. }\end{array}$ & $\begin{array}{l}\text { Variable según el grado } \\
\text { de completitud del objeto } \\
\text { cuando fue depositado. }\end{array}$ & $\begin{array}{l}\text { Alto número de porciones } \\
\text { sin remontaje. }\end{array}$ \\
\hline Potencial informativo & $\begin{array}{l}\text { Es el escenario más fiable } \\
\text { para inferir sobre la vida } \\
\text { social habitual (enseres y } \\
\text { pertenencias domésticas, } \\
\text { rutinas y tareas, etc.). No } \\
\text { son descartables posibles } \\
\text { modificaciones durante el } \\
\text { abandono precipitado. }\end{array}$ & $\begin{array}{l}\text { Informan sobre gestos } \\
\text { deliberados (tanto } \\
\text { casos estándar como } \\
\text { atípicos) de abandono } \\
\text { de algo de determinada } \\
\text { forma para conseguir } \\
\text { algo más (intención } \\
\text { última inaccesible } \\
\text { arqueológicamente). }\end{array}$ & $\begin{array}{l}\text { Informan de la acción } \\
\text { social habitual = } \\
\text { rutinas consuetudinarias } \\
\text { dedicadas a otros fines. } \\
\text { Relación espuria con las } \\
\text { actividades originales } \\
\text { (interpretación funcional } \\
\text { problemática). }\end{array}$ \\
\hline
\end{tabular}

Tab. 1 [2] Escenarios deposicionales arquetípicos y valores tafonómicos asociados.

2014a: 103, n. 18), tanto manipulando conscientemente seres o cosas muertas (con fines mágicos o esotéricos), como implicando huesos fragmentarios inadvertidos (Brudenell y Cooper 2008: 2430; Weiss-Krejci 2012: 130). Ni todas las roturas de artefactos fueron accidentales, ni cualquier conjunto de cosas desordenadas, incompletas, desgastadas u ordinarias fue basura en el pasado. En resumen, al enfrentarnos al registro prehistórico conviene poner en cuarentena los estereotipos que esperamos hallar ('niveles de ocupación', 'tumbas', 'depósitos especiales' o 'basureros') y no asumir sin suficiente escrutinio su génesis, ni finalidad. Para ello, considerar las variables contextuales, geoarqueológicas y tafonómicas resulta fundamental (Morales 1990; Butzer 2007; Aranda et al. 2015: 75).

\subsection{Estrategia de enfoque: inducción, paradigma indiciario y estudio de caso}

Desde los años 1980 la renovación teóricometodológica en el sur de la Península Ibérica ha dinamizado el debate y confrontación de perspec- 
tivas, facilitando así alcanzar narrativas sofisticadas y autocríticas (Lull et al. 2014; Aranda et al. 2015). Por contra, en el interior y norte peninsular, salvo excepciones (p.e. Colomer et al. 1998; Rojo et al. 2005, 2008; Criado Boado 2012) la práctica arqueológica se basa en visiones consensuadas, que a menudo generan información redundante y lecturas uniformes. En todas partes los enfoques deductivos y generalistas, superadores del historicismo previo, se han consolidado como corriente predominante. Su aproximación científico-natural y experimental (Fig. 1) asume que en los fenómenos estudiados rigieron unos principios reconocibles; se enuncian (formulan) hipótesis explicativas y se prevén (deducen) unas consecuencias arqueológicas, que tratan de verificarse (contrastarse) (Criado Boado 2012: 62-71). Este procedimiento hipotético-deductivo sustenta un análisis social 'desde arriba' (Gamble 2002: 87-93 y 202-207) que explica regularidades abstractas de gran escala (procesos, formaciones sociales, estructuras) (Montón-Subías 2010: 3-4) (Fig. 1). Al privilegiar visiones panorámicas de largo recorrido temporal, la rica variabilidad interna de los fenómenos analizados necesariamente pierde resolución (Ginzburg 2013: 188-190).

Convendría confrontar tales lecturas 'macro' con otras aproximaciones operando a distinto nivel y sobre líneas de evidencia independientes, en un intento de articular narrativas multiescalares

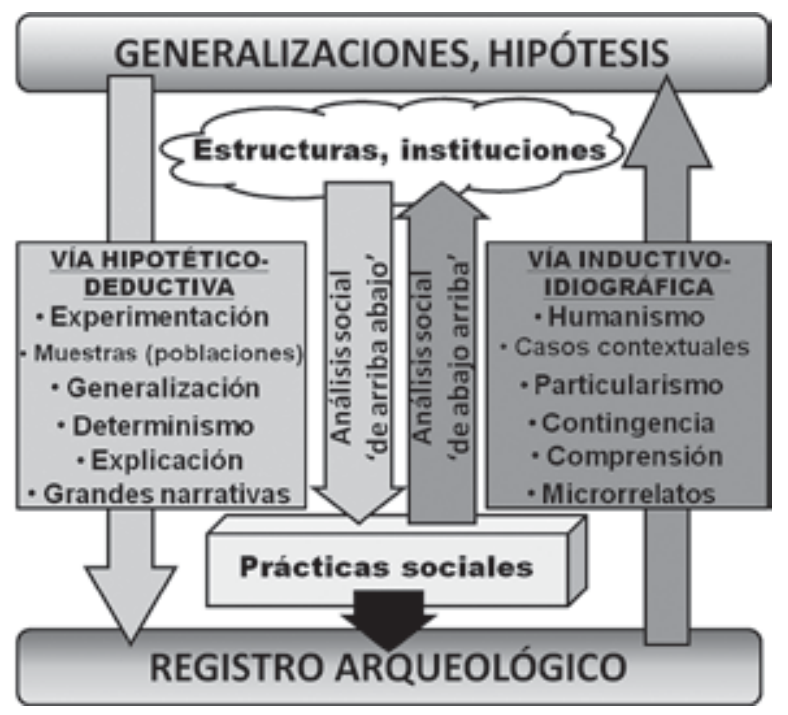

Fig. 1. Dos formas complementarias de aproximarse al registro arqueológico.
(Robb 2007; Robb y Pauketat 2013; Lillios 2015). Tal cotejo permitiría calibrar o redimensionar los relatos establecidos y no meramente completarlos o matizarlos (Wylie y Chapman 2015: 2). Para ello esta investigación se propuso recorrer el camino inferencial inverso (Fig. 1): inducir para caracterizar regularidades 'desde abajo', comprendiendo las causas a partir de los efectos, desde lo particular accesible hasta lo general desconocido (Gamble 2002: 89-95). Así hace la microhistoria, al reducir su enfoque para captar testimonios anodinos de la vida social, cuyo rastro escapa a la documentación convencional (Magnússon y Szijártó 2013). La microhistoria se basa en el paradigma indiciario o conjetural, surgido a finales del siglo XIX como alternativa al positivismo: el análisis meticuloso de pormenores inconscientes y en apariencia triviales, pero diagnósticos (pistas, síntomas, rastros), le permite adentrarse en aspectos no directamente observables (Ginzburg 2013: 183; Lucas 2012: 26-29). Semejante descripción densa o "estrategia de saturación" ha sido aplicada con éxito a la Prehistoria (Robb 2007: 23). Las concomitancias entre microhistoria y razonamiento evidencial en arqueología (p.e. Willey y Chapman 2015) son llamativas (Ortega 1999: 101-103; Ginzburg 2013: 208). La microhistoria permite además integrar lo excepcional en arqueología (Montón-Subías 2010: 1-4). Así el caso de Menocchio (Ginzburg 2001) ilustra cómo un ejemplo límite puede ser representativo: en sentido negativo contribuye a delimitar lo que debe considerarse más frecuente, y en sentido positivo "permite circunscribir las posibilidades latentes de algo que se advierte sólo a través de documentos fragmentarios y deformantes" (Ginzburg 2001: 22).

Este planteamiento se implementó mediante un estudio de caso. En Arqueología es cada vez más común referirse a tal procedimiento ${ }^{1}$, si bien como mero sinónimo de ejemplos analizados. Sin embargo, el estudio de caso es un método de investigación inductivo, idiográfico y cualitativo muy utilizado en ciencias sociales (Stake 1995; Gillham 2000; Yin 2003) y aplicable en Arqueología dentro de tal aproximación si consideramos sus requisitos y limitaciones. Esta herramienta persigue la comprensión contextual (en circunstancias singulares)

\footnotetext{
${ }^{1}$ A menudo referidos en español, incorrectamente, como 'casos de estudio', por transposición directa del inglés case study.
} 
de fenómenos sociales mediante la generalización analítica de proposiciones teóricas (Yin 2003: 10). Es decir, en lugar de obtener muestras estadísticamente representativas de unas poblaciones desconocidas, parte de ejemplos singulares de la realidad objeto de análisis. La descripción exhaustiva de los casos y su cotejo con los presupuestos iniciales intenta expandirlos, matizarlos o desmentirlos. Los fenómenos estudiados deben cumplir ciertas condiciones (Gillham 2000: 1-14; Yin 2003: 12-15): a) de los que conocemos poco y lo que creemos saber es revisable; b) que no admiten experimentos y cuyo entorno de recogida de datos no es controlado por el investigador; c) configurados por múltiples variables, de las cuales sólo podemos analizar una selección; y d) que requieren diversas fuentes de información concurrentes. Su empleo en investigación es uno de los mayores retos en ciencias sociales (Yin 2003: 1); el diseño del estudio y la interpretación de los casos no pueden trivializarse; deben ser rigurosos y verificables, y no discrecionales e intuitivos como hacemos en arqueología.

El área de estudio elegida abarca las Cuencas del Duero y el Alto Tajo (Fig. 2), ya que debía ser amplia y contar con un nivel uniforme de trabajo de campo. En esta zona la información, recuperada mediante estrategias intensivo-académicas y extensivo-preventivas, pudiera considerarse una muestra cuasi-aleatoria, pero no puede establecerse el universo completo del que procede. Como alternativa al muestreo probabilístico del enfoque experimental (Fig. 1), se optó por un estudio de caso múltiple (Yin 2003: 46-55), que permitir replicar las observaciones, bien para predecir resultados similares o para hallar resultados divergentes bajo otras condiciones (Yin 2003: 47). Se eligieron estratégicamente ocho sitios datados entre el Neolítico Antiguo (c. $5500 \mathrm{cal} \mathrm{AC)} \mathrm{y} \mathrm{el} \mathrm{Bronce} \mathrm{Final} \mathrm{(c.} 1100$ cal AC), que incluían variados contextos deposicionales ${ }^{2}$ (cabaña, tumba, monumento, fosas) para facilitar la comparación de resultados (Tab. 2). Esos contextos debían contar con: a) excavación completa de los mismos; b) registro estratigráfico y documentación de calidad; c) recogida exhaustiva de materiales, accesibles para su estudio en museos; y d) que plantearan aspectos a aclarar. Entre los

\footnotetext{
2 Son un total de 60 contextos, repartidos por épocas así: 8 neolíticos; 15 calcolíticos; 14 del Bronce Medio y 23 del Bronce Final.
}

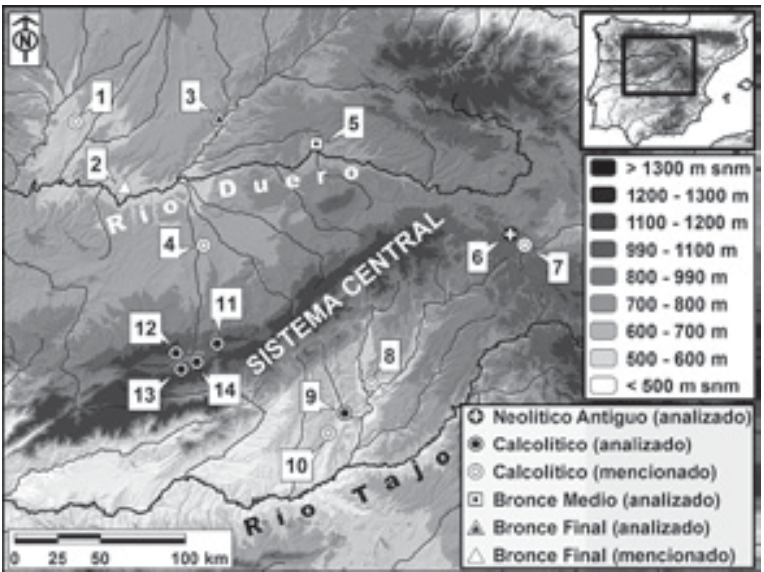

Fig. 2. Área de estudio en la Península Ibérica sobre cartografía SRTM (Shuttle Radar Topography Mission de la $N A S A$ ). Sitios mencionados: 1. Molino Sanchón II (Villafáfila, Zamora); 2. La Requejada (San Román de Hornija, Valladolid); 3. Pico Castro (Dueñas, Palencia); 4. La Calzadilla (Almenara de Adaja, Valladolid); 5. El Cerro (La Horra, Burgos); 6. La Lámpara (Ambrona, Soria); 7. El Alto III (Medinaceli, Soria); 8. Camino de las Yeseras (San Fernando de Henares, Madrid); 9. El Ventorro (Madrid); 10. Humanejos (Parla, Madrid); 11. Valdeprados (Ávila); 12. Los Tiesos I (Ávila); 13. Fuente Lirio (Muñopepe, Ávila); 14. El Morcuero (Gemuño, Ávila).

casos están representadas numerosas fosas o estructuras negativas, por ser los contextos más frecuentes y más difíciles de interpretar.

Los ámbitos fisiogénicos estables (campiñas, valles fluviales y páramos) en que se localizan los sitios (Fig. 2) han conllevado débiles perturbaciones posdeposicionales naturales (escorrentía superficial, bioturbación) (Schiffer 1987: 121-133; Butzer 2007: 142-159). Estamos ante depósitos eminentemente antropogénicos (c-transforms) (Schiffer 1987: 25-98) en cuya configuración los factores naturales (n-transforms) contribuyeron a escala mucho menor y una vez ya formados los sedimentos. Hay consenso en que hoyos, cubetas $\mathrm{y}$ fosos se rellenaron relativamente rápido con detritos vertidos por humanos; los depósitos de objetos o cadáveres y su colmatado tampoco se dilataron en el tiempo, mientras que la génesis de las cabañas prehistóricas, con la información publicada, resulta oscura. 


\begin{tabular}{|c|c|c|c|c|c|c|c|c|c|c|c|c|c|c|}
\hline Nombre & Período & $\begin{array}{c}\text { Tipo de } \\
\text { yacimiento }\end{array}$ & $\begin{array}{l}\text { Contextos } \\
\text { estudiados }\end{array}$ & $\begin{array}{l}\text { Área } \\
\left(m^{2}\right)\end{array}$ & $\begin{array}{l}\text { NR tot } / \\
\text { NR est }\end{array}$ & $\begin{array}{l}\text { Frag. } \\
\text { casan }\end{array}$ & NM & $\begin{array}{l}\text { Frag. no } \\
\text { casan }\end{array}$ & Peq & Med & Gra & No $r$ & $\mathrm{Al} \mathrm{r}$ & Ddo \\
\hline La Lámpara & $\begin{array}{l}\text { Neolítico } \\
\text { Antiguo }\end{array}$ & $\begin{array}{c}\text { Campo de } \\
\text { hoyos en llano }\end{array}$ & $\begin{array}{c}\text { Hoyos } 1,2,3,9 \\
10,13,17 \text { y } 18\end{array}$ & 1250 & $\begin{array}{c}1349 \\
(100 \%)\end{array}$ & $\begin{array}{c}354 \\
(26 \%)\end{array}$ & 64 & $\begin{array}{l}995 \\
(74 \%)\end{array}$ & $35 \%$ & $43 \%$ & $22 \%$ & $83 \%$ & $11 \%$ & $6 \%$ \\
\hline Fuente Lirio & Calcolítico & Asentamiento & $\begin{array}{c}\text { Cabaña y } 5 \text { hoyos } \\
\text { en Sector } 1\end{array}$ & 94 & $\begin{array}{c}2856 \\
(100 \%)\end{array}$ & $\begin{array}{c}1382 \\
(48 \%)\end{array}$ & 140 & $\begin{array}{l}1474 \\
(52 \%)\end{array}$ & $7 \%$ & $52 \%$ & $34 \%$ & $92 \%$ & $5 \%$ & $3 \%$ \\
\hline El Ventorro & Calcolítico & $\begin{array}{l}\text { Recinto fosado } \\
\text { en llano }\end{array}$ & $\begin{array}{c}\text { Hoyos } 08,09,010 \\
011,012 \\
\text { y Cabaña } 013\end{array}$ & 44 & $\begin{array}{l}36578 \\
/ 3837 \\
(11 \%)\end{array}$ & $\begin{array}{c}730 \\
(19 \%)\end{array}$ & 310 & $\begin{array}{c}3107 \\
(81 \%)\end{array}$ & $55 \%$ & $42 \%$ & $3 \%$ & $60 \%$ & $39 \%$ & $1 \%$ \\
\hline Valdeprados & Calcolítico & Fosa aislada & $\begin{array}{l}\text { Enterramiento } \\
\text { campaniforme }\end{array}$ & 20 & $\begin{array}{c}254 \\
(100 \%)\end{array}$ & $\begin{array}{c}78 \\
(31 \%)\end{array}$ & 16 & $\begin{array}{l}176 \\
(69 \%)\end{array}$ & $22 \%$ & $65 \%$ & $13 \%$ & $63 \%$ & $21 \%$ & $16 \%$ \\
\hline Los Tiesos I & Calcolítico & Túmulo & $\begin{array}{l}\text { Monumento } \\
\text { completo }\end{array}$ & 116 & $\begin{array}{c}236 \\
(100 \%)\end{array}$ & $\begin{array}{c}51 \\
(21 \%)\end{array}$ & 29 & $\begin{array}{c}185 \\
(79 \%)\end{array}$ & $32 \%$ & $62 \%$ & $6 \%$ & $11 \%$ & $57 \%$ & $32 \%$ \\
\hline $\begin{array}{c}\text { El } \\
\text { Morcuero }\end{array}$ & Calcolítico & Túmulo & $\begin{array}{l}\text { Monumento } \\
\text { completo }\end{array}$ & 80 & $\begin{array}{c}543 \\
(100 \%)\end{array}$ & $\begin{array}{c}124 \\
(23 \%)\end{array}$ & 45 & $\begin{array}{c}419 \\
(77 \%)\end{array}$ & $26 \%$ & $66 \%$ & $8 \%$ & $14 \%$ & $59 \%$ & $27 \%$ \\
\hline El Cerro & $\begin{array}{l}\text { Bronce } \\
\text { Medio }\end{array}$ & $\begin{array}{c}\text { Campo de } \\
\text { hoyos en llano }\end{array}$ & $\begin{array}{l}\text { Hoyos } 2,4,6,10, \\
11,14,15,17,22, \\
23,24,25,27 \text { y } 29\end{array}$ & 550 & $\begin{array}{l}1441 \\
/ 312 \\
(22 \%)\end{array}$ & $\begin{array}{c}144 \\
(46 \%)\end{array}$ & 123 & $\begin{array}{c}168 \\
(54 \%)\end{array}$ & $47 \%$ & $30 \%$ & $23 \%$ & $72 \%$ & $26 \%$ & $2 \%$ \\
\hline Pico Castro & $\begin{array}{l}\text { Bronce } \\
\text { Final }\end{array}$ & $\begin{array}{l}\text { Campo de } \\
\text { hoyos en alto }\end{array}$ & $\begin{array}{c}\text { Sector IV } \\
\text { (9 hoyos) y Sector } \\
\text { V (14 hoyos) }\end{array}$ & 250 & $\begin{array}{c}1410 \\
(100 \%)\end{array}$ & $\begin{array}{c}267 \\
(19 \%)\end{array}$ & 84 & $\begin{array}{l}1143 \\
(81 \%)\end{array}$ & $12 \%$ & $45 \%$ & $43 \%$ & $66 \%$ & $29 \%$ & $5 \%$ \\
\hline
\end{tabular}

Tab. 2. Resultados de tafonomía cerámica. NR tot: número total de restos / NR est: NR estudiados; NM: número mínimo de vasijas; Frag.: Fragmentos; Tamaño: pequeño (Peq) $\left(<12,5 \mathrm{~cm}^{2}\right)$; mediano (Med) $\left(12,5-66,5 \mathrm{~cm}^{2}\right)$ y grande (Gra) ( $>66,5 \mathrm{~cm}^{2}$ ). Erosión: no rodado (No r) (fracturas cortantes, superficies intactas); algo rodado (Al r) (cantos pulidos, caras afectadas) y desgastado (Ddo) (roturas redondeadas, pérdida de superficies). A partir de Blanco-González 2014a: tabs. 1 y 2.

\subsection{Metodología de análisis: tafonomía cerámica y arquetipos deposicionales}

Para caracterizar las dinámicas de formación de los contextos estudiados las observaciones estratigráficas son insuficientes y su información geoarqueológica irrecuperable. Por ello se recurrió a los materiales hallados en sus matrices de sedimento, entre los cuales destaca la cerámica, el material imperecedero más frecuente, cuya capacidad informativa está infrautilizada. Este objetivo quedaba en una 'tierra de nadie' metodológica. El estudio actualista de la alfarería mediante etnoarqueología permite relacionar huellas de uso y residuos orgánicos con costumbres culinarias (Skibo 1992). En el caso de la vajilla prehistórica, tal enfoque traceológico queda limitado a circunstancias óptimas de conservación, debido a su desgaste preabandono (reciclado, pisoteo, meteorización, etc.) (cf. Stark 2003: 210; Chapman y Gaydarska 2007: 73-77), más perturbación química y biológica posdeposicional, que encubren o eliminan tales indicadores. Así pues, el enfoque necesario está más próximo de la tafonomía, y así se ha comenzado a denominar (Wolfram 2013). Ante la falta de criterios consensuados de caracterización tafonómica y de remontaje cerámico (Brudenell y Cooper 2008; Rídký et al. 2014), se diseñó un protocolo propio, que tras su ensayo con la cerámica de El Ventorro (Blanco-González 2014a) se aplicó sistemáticamente al resto de colecciones. Se adoptó como unidad de análisis el fragmento cerámico $(\mathrm{n}=10.797)$, y se estudiaron todos los fragmentos hallados en los 40 contextos deposicionales de seis sitios, mientras que se seleccionó una muestra de El Ventorro y El Cerro (Tab. 2). Se registraron numéricamente una serie de variables ${ }^{3}$ según los criterios expuestos y discutidos detalladamente en el mencionado trabajo (Blanco-González 2014a: 93-95) (Tab. 2). El tamaño (expresado en $\mathrm{cm}^{2}$ ) se midió con una plantilla con celdillas preestable-

\footnotetext{
${ }^{3}$ Algunas variables se han simplificado aquí para facilitar su presentación y comparación.
} 
cidas a partir del mencionado estudio preliminar (Blanco-González 2014a: tabla 2); la variable ordinal erosión se codificó evaluando la afección de los cantos y superficies de las piezas (Tab. 2); el número de trozos huérfanos o sin remontaje local y de piezas que conciertan consideró tanto las asociaciones seguras como posibles; el número mínimo de recipientes es una estimación muy a la baja, a partir del total de porciones asociadas a una misma vasija.

A partir del conocimiento actual de los procesos formativos (Schiffer 1987; LaMotta y Schiffer 1999; Chapman y Gaydarska 2007; Jiménez Jáimez 2008), la etnoarqueología (Hayden y Cannon 1983; Cameron y Tomka 1993; Arnold 2000; Stark 2003) y las experiencias de trabajo posexcavación (Brudenell y Cooper 2008; Wolfram 2013; Rídký et al. 2014) se esbozaron algunos supuestos ideales y sus valores tafonómicos asociados (Tab. 1) con los que cotejar los resultados obtenidos (Tab. 2). Esos arquetipos ayudan a comprender la rica casuística arqueológica resultante de la vida social prehistórica (Fig. 3). Para adentrarnos en este terreno, conviene distinguir primeramente entre 'productos', que conservan asociaciones significativas entre sus componentes y 'efectos' derivados o agregados aleatorios de restos. Así, por un lado los correlatos materiales fruto de prácticas sociales deliberadas (Fig. 3A) pueden ser 'productos' o 'efectos': los primeros (Fig. 3A1) resultan de la voluntad explícita de manipular cosas o seres con cierta formalidad (p.e. enterrarlos), singularizando tales acciones (Brück 1999: 325-329; Garrow 2012: 104-106) para visibilizarlos u ocultarlos (Criado Boado 2012: 271-274, Fig. 43). Evito el término 'depósito estructurado' (structured deposition) porque es equívoco (Garrow 2012) y añadiría más confusión que ventajas. Los 'efectos' acumulativos (Fig. 3A2) ocurrieron al tratar de alcanzar otros propósitos. Garrow (2012: 109-113) los llama material culture patterning y en este estudio constituyen el principal escenario creador de registro arqueológico, a pesar de lo cual sabíamos muy poco sobre ellos (Garrow 2012: 105), por lo que al avanzar en esta investigación consideré prioritario caracterizarlos. Por otro lado, los correlatos materiales no planificados (Fig. 3B) ocurridos de la vida social rutinaria (Criado Boado 2012: 271, n. 323) también pueden ser 'productos' (Fig. 3B1) o 'efectos' derivados, no considerados aquí (Fig. 3B2).

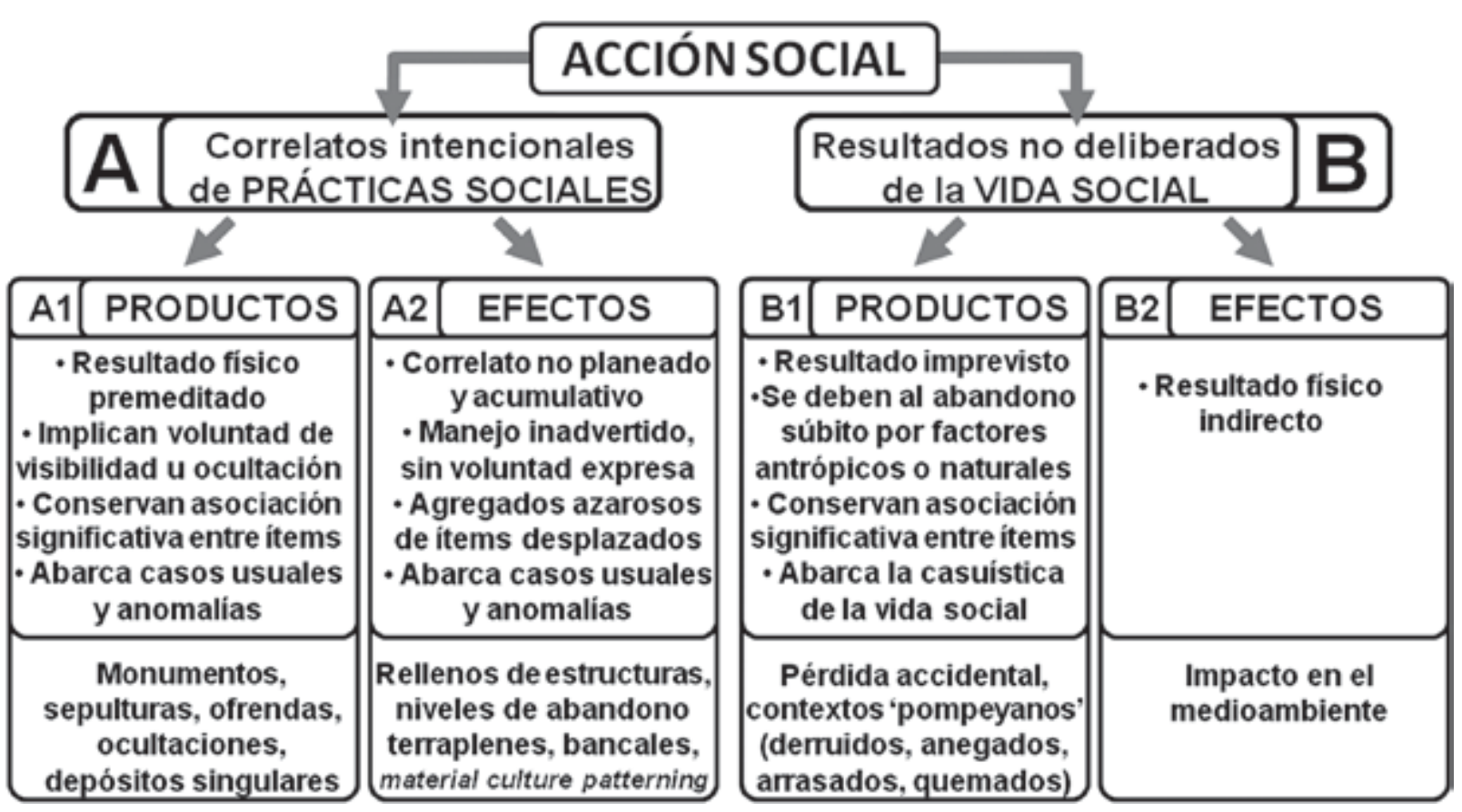

Fig. 3. Relación entre acción social y resultados arqueológicos (a partir de Criado Boado 2012: 272, Fig. 43, modificado y matizado).

Trab. Prehist., 73, N. ${ }^{\circ}$ 1, enero-junio 2016, pp. 47-67, ISSN: 0082-5638

doi: $10.3989 /$ tp.2016.12163 


\section{RESULTADOS: MICROHISTORIAS A PARTIR DE PISTAS CERÁMICAS}

Debido al alto número de materiales estudiados, su presentación aquí ha priorizado los resúmenes numéricos (en porcentajes) referidos a los yacimientos en bloque (Tab. 2), en lugar de a sus contextos deposicionales individuales (fosas, UUEE). Una sencilla exploración estadística permite valorar a qué responde la muestra analizada, que no cumple los exigentes criterios de las pruebas paramétricas (simetría de variables, normalidad de la población). Así, considerando toda la cerámica estudiada $(\mathrm{n}=10.797$ fragmentos de los 60 contextos) independientemente de si son selecciones parciales $(\mathrm{NR}$ est. $=11-100 \%)$, se recurrió a pruebas no paramétricas para comprobar si los resultados del remontaje (fragmentos que no casan) dependen del tamaño de las muestras (NR est.) (Tab. 2). El test del coeficiente de correlación $\rho$ de Spearman permite rechazar la $\mathrm{H}_{0}$ y afirmar una fuerte asociación lineal entre ambas variables $(\rho=, 905$ y $p=, 002)$. Un análisis de regresión simple, siguiendo experiencias previas de caracterización del contenido de hoyos prehistóricos (Díaz-del-Río 2001: 53-59), muestra una correlación lineal significativa que explica el 93\%

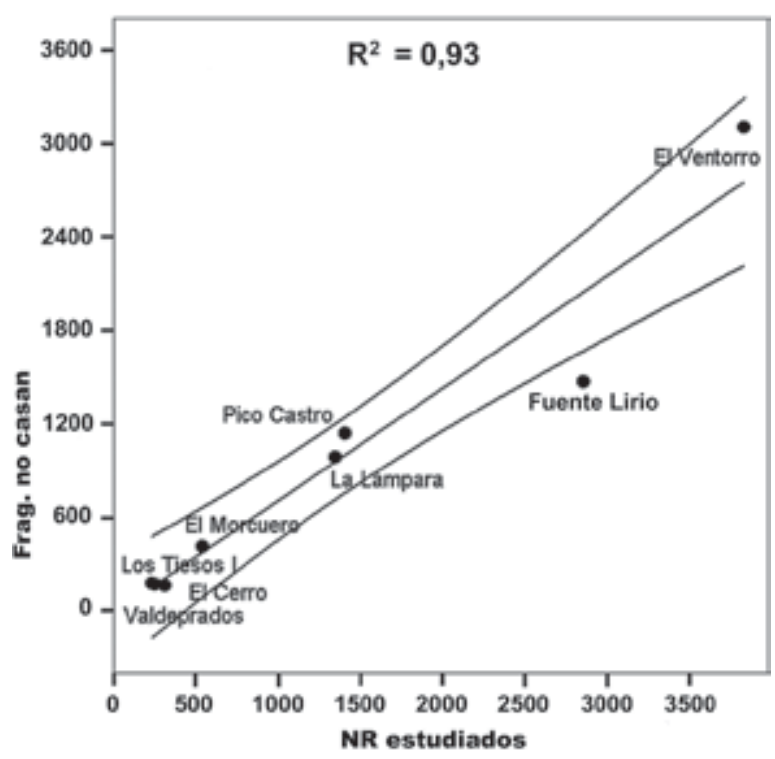

Fig. 4. Regresión lineal entre las variables de tamaño de la muestra (NR est.) y fragmentos huérfanos (Frag. no casan). Intervalo de predicción de la media al 95\%. de la variabilidad (Fig. 4). Es decir, el número de fragmentos huérfanos depende del tamaño de la muestra en todos los casos salvo en Fuente Lirio, un tipo de contexto - cabaña- que claramente responde a otra dinámica formativa. En suma, podemos afirmar que en las poblaciones originales de las que proceden estas muestras no hay diferencias por épocas, pero sí entre tipos de contextos deposicionales, y salvo casos particulares, cuanta más cerámica estudiemos, más fragmentos huérfanos encontraremos. A continuación se examinarán algunos aspectos destacados por épocas.

\subsection{Neolítico Interior (c. 5500-3300 cal AC)}

Tras un mayor peso de la arqueología de la muerte (megalitos de finales del $\mathrm{V}$ y todo el IV milenio AC) a expensas de la arqueología de los asentamientos, actualmente los testimonios neolíticos meseteños abarcan mayor casuística y un arco temporal envejecido (Díaz-del-Río 2001; Bueno et al. 2012a; Garrido Pena et al. 2012b). Las ocupaciones, al aire libre y en cuevas (Jiménez Guijarro 2010: 592-593), son mayoritariamente del Neolítico Antiguo (c. 5500-4400 cal AC), mientras que las fases recientes están infrarrepresentadas (Garrido Pena et al. 2012b: 475; Balsera et al. 2015: 141-142) y respondieron a la interacción entre grupos colonos (Jiménez Guijarro 2010: 591) y el sustrato mesolítico (Hernando 1999: 340-342; Bueno et al. 2012a: 520) en diversas combinaciones (Rojo et al. 2008: 318-335). Respecto a los testimonios mortuorios, además del megalitismo del Neolítico Medio y Final, desde mediados del VI milenio AC se conocen restos humanos en fosa, tanto articulados (Garrido Pena et al. 2012a: 148150) como desmembrados (Weiss-Krejci 2012: 129-130), siguiendo costumbres muy extendidas en otras regiones europeas (p.e. Robb 2007: 58).

La alfarería fue crucial entre las más tempranas comunidades agropastoriles. Su decoración cerámica se ha relacionado con el almacenaje de alimentos (Jiménez Guijarro 2010: 595), pero la estima cultural de algunos recipientes sobrepasaría tales fines instrumentales (cf. Robb 2007: 161-186). La Lámpara (Soria) (Fig. 2, nº 6) fue un campamento temporal visitado durante la segunda mitad del VI milenio AC (Rojo et al. 2008). De 
los 18 hoyos descubiertos algunos fueron silos, y todos ellos finalmente se colmataron con desechos de actividades cotidianas. La rotura deliberada de vasijas y el depósito selectivo de materiales fueron gestos característicos en su clausura (Rojo et al. 2008: 375-378). La revisión tafonómica

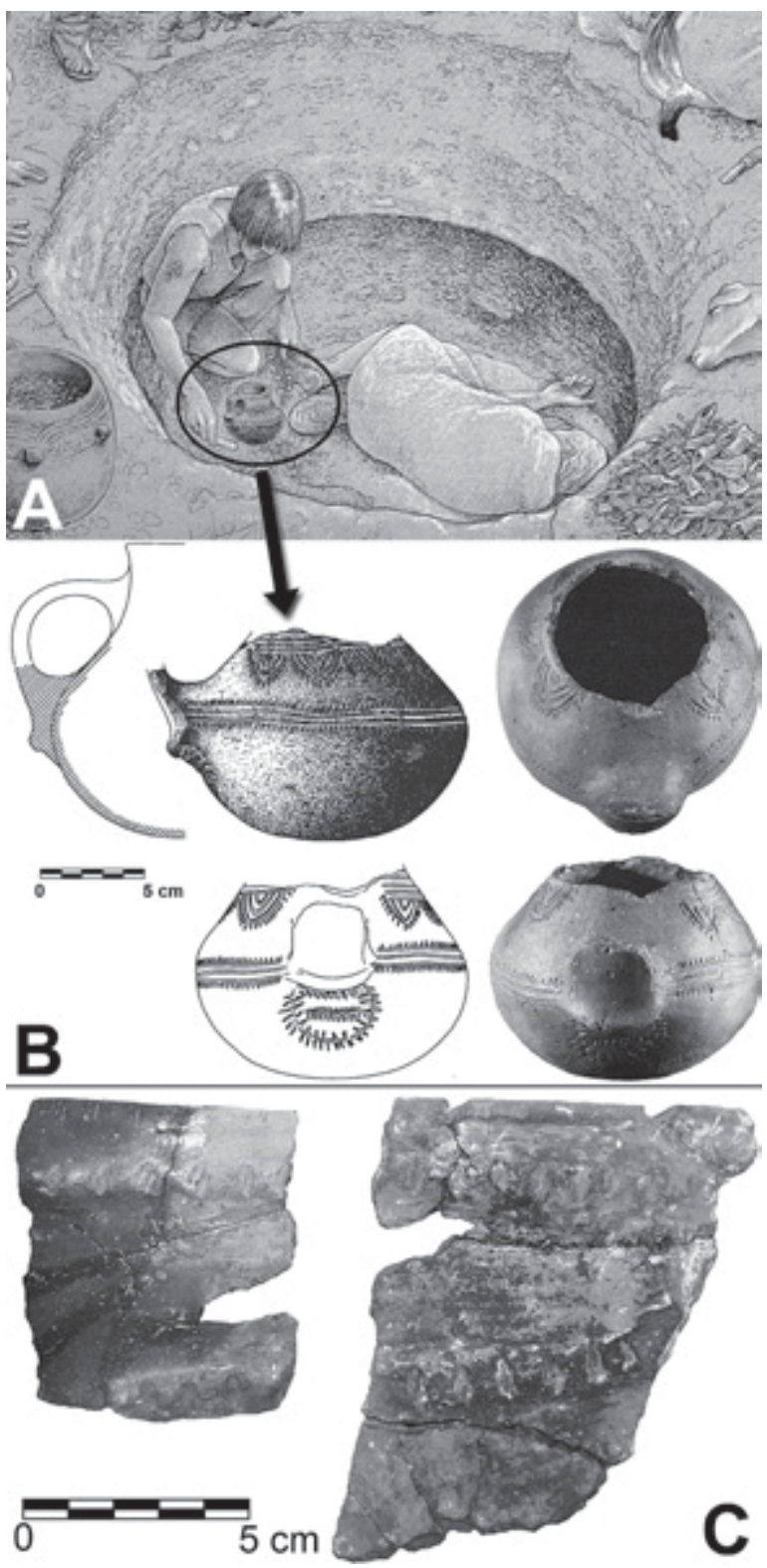

Fig. 5. Neolítico Antiguo. A. Enterramiento del hoyo 1 de La Lámpara (Rojo et al. 2008: 84). B Jarro con tatuaje facial al que le falta la embocadura (Rojo et al. 2008: 377, Fig. 186). C. Fragmentos análogos de dos orzas del hoyo 13 (foto A. Blanco). de la cerámica (Tab. 2) confirma tales extremos. La mayoría de la cerámica (el 83\%) exhibe una buena conservación -fue desechada poco antes. Seis de las fosas están vinculadas por fragmentos concertantes. La alta proporción de fragmentos de tamaño pequeño-medio (78\%) indican su pisoteo durante sucesivas reocupaciones. El entierro de una anciana en el hoyo 1 (Fig. 5A) involucró ciertas formalidades (Rojo et al. 2008: 81-86 y 379393): a sus pies se colocó un jarro antropomórfico sin cuello (Fig. 5B), roto adrede -fractura neta, su pesado fondo carece de las marcas de impacto frecuentes en roturas accidentales (Tab. 1)- realzando así un rostro humano o tatuaje facial inciso (Rojo et al. 2008: 377-379) (Fig. 5B). Se reconocieron más gestos deliberados en la clausura del hoyo 1: en el sedimento que cubría el cadáver se hallaron 246 fragmentos cerámicos con roturas frescas, de los que 126 conciertan con otros y pertenecen a unos 21 recipientes, todos parciales y probablemente rotos o 'matados' (VVAA 2003: 97-115) durante la ceremonia funeraria (Rojo et al. 2008: 388).

La presencia en los hoyos de porciones de las mismas vasijas, a veces con llamativos contrastes de alteración pos-rotura, planteó si se asociaron a propósito. El análisis petrográfico de pares de trozos supuestamente del mismo recipiente aclaró este aspecto (Blanco-González et al. 2014). En el hoyo 13 aparecieron dos fragmentos señeros por su tamaño y decoración plástica (Fig. 5C), sensatamente publicados como de una misma orza (Rojo et al. 2008: 140, Fig. 115, $\mathrm{n}^{\mathrm{o}} 1$ ); sin embargo, procedían de dos vasijas. Pudiera ser casualidad, pero ambas porciones difícilmente pasaron desapercibidas para quienes las descartaron.

\subsection{Calcolítico y Campaniforme (c. 3300-2200 cal AC)}

El III milenio AC en la Península Ibérica ha legado un rastro mucho más visible e investigado que el precedente. Hay indicios de una acentuación de la actividad humana, como el abrupto incremento de fechas de radiocarbono c. $2900 \mathrm{cal}$ AC en el mediodía peninsular (Balsera et al. 2015: 142). Se conocen poblados al aire libre, recintos fosados, múltiples fórmulas funerarias, arte rupes-

Trab. Prehist., 73, N. ${ }^{\circ}$ 1, enero-junio 2016, pp. 47-67, ISSN: 0082-5638

doi: $10.3989 /$ tp.2016.12163 
tre, monumentos, etc. (Díaz-del-Río 2001; Rojo et al. 2005; Bueno et al. 2012b).

En Fuente Lirio (Ávila) (Fig. 2, no 12) se documentó una cabaña de $6 \mathrm{~m}$ de diámetro con hogar y dos fases de ocupación (Fabián 2006: 128-155). La colección cerámica $(\mathrm{n}>2.800)$ permitió reconocer unos 140 cuencos, ollas y orzas en perfecto estado (92\%), predominando los tamaños medianos y grandes (86\%) y casi la mitad conciertan entre sí (Tab. 2). Este resultado cuadra bien con lo esperable en un repertorio comensal roto y abandonado en un intervalo corto, pero no responde a un 'depósito pompeyano' (Tab. 1): el $8 \%$ de las piezas están algo o muy erosionadas pos-rotura y pese a la excavación completa de la cabaña, el 52\% son trozos huérfanos. Es decir, que ni los recipientes se rompieron in situ ni son desechos de facto. Además este conjunto tiene menos fragmentos huérfanos que los previsibles según el modelo lineal que explica el 95\% del total de cerámicas estudiadas (Fig. 4). No es posible aún barajar variables como la vida de uso o la tasa de reposición de recipientes (Arnold 2000: 114-118; Stark 2003: 209-210), pero el volumen de vajilla hallado excede lo esperable en un grupo familiar. Este patrón distintivo cabe interpretarse como una inusual acumulación de vasijas, tal vez empleadas en la celebración de clausura de esta cabaña (LaMotta y Schiffer 1999: 22-24; Jiménez Jáimez 2008: 130-131; Waddington 2014); pudieron romperse fuera de la vivienda (proporción anómala de fragmentos sin remontaje) y finalmente fueron arrojadas a la misma poco tiempo después (porciones grandes y no erosionadas).

Esta imagen contrasta vivamente con la "cabaña 013' de El Ventorro (Madrid) (Fig. 2, no 9). De este extraordinariamente rico y variado depósito (n > 39.700 ítems) (Díaz-del-Río 2001: 237-250) se examinó una selección $(\mathrm{n} \sim 4.000$ fragmentos), incluyendo 111 trozos cerámicos de unos 48 recipientes con decoración campaniforme (Blanco-González 2014a) (Tab. 2). La 'cabaña 013' fue interpretada inicialmente como una sucesiva acumulación de suelos de ocupación limpiados periódicamente (Priego y Quero 1992: 118). De ser así, apenas encontraríamos unos pocos microdesechos (LaMotta y Schiffer 1999: 21). Las observaciones tafonómicas (Tab. 2) muestran un agregado heterogéneo de restos: un $60 \%$ son de reciente rotura y sólo el 3\% son trozos grandes. El estudio de caso múltiple muestra aquí su uti- lidad, al cotejar contextos bajo condiciones supuestamente homogéneas (Yin 2003: 47). Así, en Fuente Lirio el $7 \%$ eran piezas pequeñas frente al $55 \%$ en El Ventorro, y los residuos erráticos en el primero rondan el $8 \%$ frente al $40 \%$ en el segundo (Tab. 2). Valores tan divergentes entre tales 'efectos' de prácticas sociales (Fig. 3A2) sugieren condiciones de formación y temporalidades muy distintas. La 'cabaña 013' parece ser un segmento de foso (Díaz-del-Río 2001: 249) colmatado con desechos cuyo patrón de tafonomía cerámica (mezcla de materiales con muy diversas historias deposicionales) es comparable al de otros fosos monumentales neolíticos (Rídký et al. 2014: 595596). En todo caso, el modelado bayesiano de las dataciones radiocarbónicas del cercano recinto de Camino de las Yeseras (Fig. 2, n ${ }^{\circ} 8$ ) sugiere un uso y amortización de los fosos en periodos de hasta 40 años (Balsera et al. 2015: 153). Así pues, en El Ventorro ciertas vasijas campaniformes pudieron haber sido usadas y rotas durante banquetes (Garrido Pena et al. 2011) celebrados por una misma generación de comensales. Un detalle es llamativo; la cuarta parte de esos fragmentos campaniformes -algunos con motivos esquemáticos como soles y ciervos considerados simbólicos (Garrido Pena y Muñoz 2000)- están tan degradados como el resto de desperdicios. Así pues, en su fase terminal tales bienes de prestigio no recibieron ningún trato distintivo.

La fosa de Valdeprados (Ávila) (Fabián 2006: 353-362) es un enterramiento campaniforme extraño, con los restos reducidos de un varón y elementos de prestigio como una chapita de oro, un puñal de lengüeta y tres puntas Palmela. De 254 fragmentos cerámicos hallados, el $69 \%$ son huérfanos (Tab. 2). Se reconstruyeron casi completos un vaso campaniforme (Fig. 6A) y un cuenco lisos, cuyos patrones de fractura - grietas radiales desde un punto de impacto (cf. Tab. 1)- indican que se rompieron por un golpe violento y allí mismo. Hay otros recipientes parciales, como medio cuenco (Fig. 6B) o una porción de vasija común con sus cantos pulidos, tal vez reusada como cucharón (Fig. 6C). El intenso desgaste de los 30 pedazos de tres vasos campaniformes Ciempozuelos (Fig. 6D) cuestiona que se usaran en la ceremonia mortuoria (contra Garrido Pena et al. 2011: 125); parecen residuos con afecciones más dilatadas e intensas. Ciertas formalidades detectadas en Valdeprados se reprodujeron también en un 
hoyo de La Calzadilla (Valladolid) (Fig. 2, no 4): restos humanos y animales desmembrados comparecen junto a cinco mitades de cuencos (Liesau et al. 2014b: 94). La destrucción deliberada e in situ de campaniformes queda atestiguada en un pozo del sector 1F de Molino Sanchón II (Zamora) (Fig. 2, $\mathrm{n}^{\mathrm{o}} 1$ ), al que se arrojó un gran vaso carenado (Fig. 7) (Abarquero et al. 2012: 332). La recuperación de restos fragmentarios de vasijas campaniformes y su (re)deposición selectiva está bien atestiguada en túmulos como El Alto III

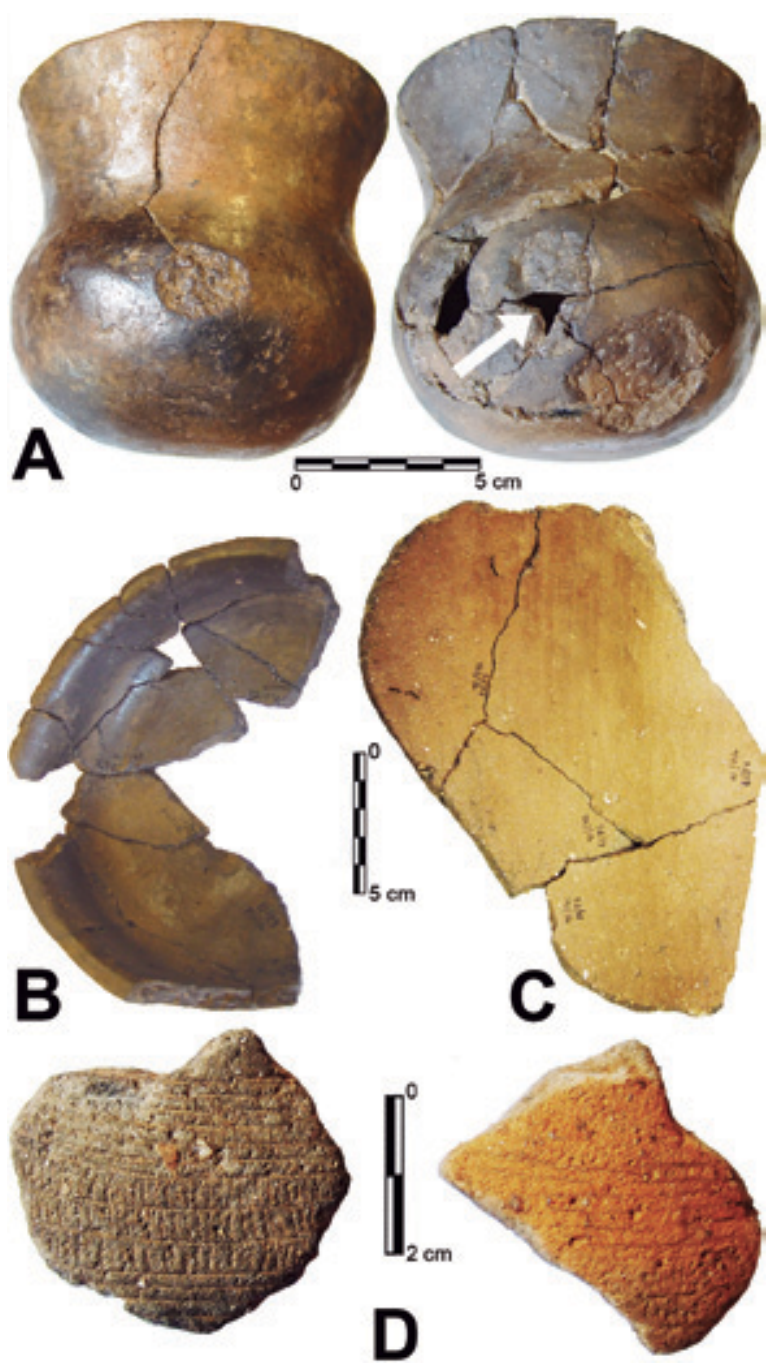

Fig. 6. Fosa calcolítica de Valdeprados (Ávila). A. Vaso campaniforme liso, se indica el punto de impacto. B. Media porción de cuenco. C. Porción de vasija reutilizada, con rotura izquierda pulida. D. Trozos muy desgastados de un vaso campaniforme inciso (fotos A. Blanco).

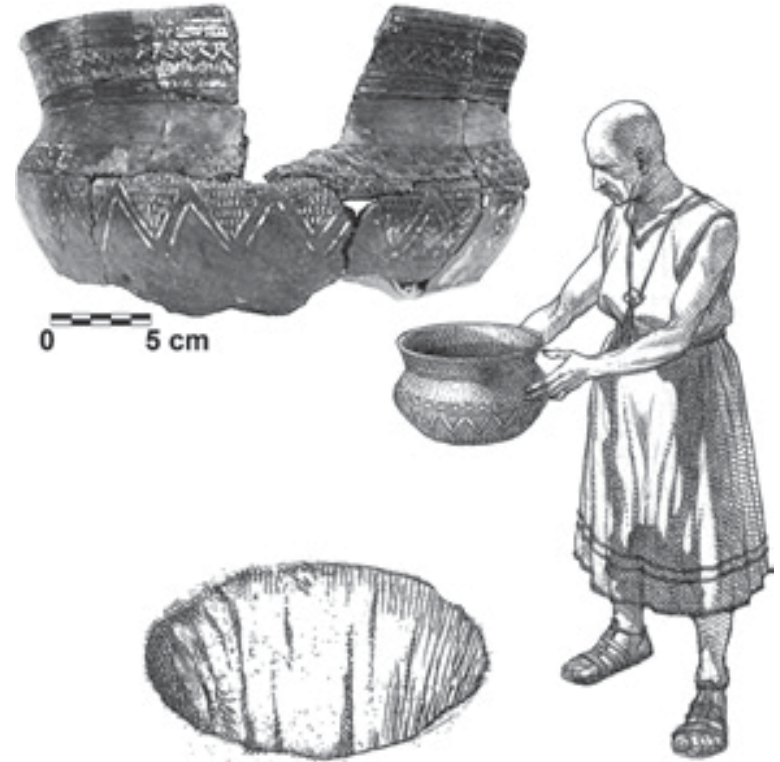

Fig. 7. Molino Sanchón II (Zamora). Gran vaso campaniforme arrojado a una fosa (a partir de Abarquero et al. 2012: 331, lám. 164).

(Soria) (Fig. 2, no 7) (Rojo et al. 2014: 33-34) o Los Tiesos I y El Morcuero (Ávila) (Fig. 2, $\mathrm{n}^{\mathrm{o}}$ 11 y 13); estos dos últimos con numerosos restos huérfanos $(>75 \%)$ y muy desgastados $(\sim 30 \%)$ (Tab. 2), indicando su rotura fuera del túmulo y un prolongado desgaste.

Por último, algunos recipientes campaniformes parciales también sugieren su destrucción intencional con otros fines. En Humanejos (Madrid) (Fig. 2, $n^{\circ} 10$ ), un espectacular hipogeo y una gran fosa fueron saqueados y sus contenidos destrozados y dispersados en época campaniforme, tal vez en un intento de anular la memoria de los allí enterrados, en un contexto de disputa entre facciones (Flores-Fernández y Garrido-Pena 2014).

\subsection{Bronce Medio y Final (c. $1800-1100$ cal AC)}

En la Meseta el II milenio AC está representada por Cogotas I, cuya impronta material es más tenue que la precedente (Barroso et al. 2014: 122123). Los testimonios de actividades domésticas se reducen a restos redepositados en los hoyos que salpican la mitad norte peninsular (Colomer et al. 2008: 58). La costumbre de desmantelar 
las viviendas, reciclar y dispersar los desechos (Fernández-Posse 1998: 241) condicionó su rara conservación. El ritual normativo de la exposición del cadáver (Esparza et al. 2012b) también nos ha privado del grueso de la evidencia osteológica (Barroso et al. 2014: 122). A tal invisibilidad contribuyó decisivamente una estrategia de ocultación (Criado Boado 2012: 286; Blanco-González 2015). Además, la suma de probabilidades del radiocarbono calibrado dibuja una curva descendente, muy acusada desde c. $1500 \mathrm{cal}$ AC (Balsera et al. 2015: 144, Fig. 4), que pudiera indicar cierto estancamiento demográfico. En ausencia de tumbas y viviendas normativas, acercarse a las formas de vida de tales grupos demanda estrategias no convencionales (Blanco-González 2015).

El Cerro (Burgos) es un campo de hoyos Protocogotas en la llanura (c. 1700-1500 cal AC) (Fig. 2, $\mathrm{n}^{\mathrm{o}} 5$ ), incluido aquí por sus inusuales hallazgos: restos de al menos una cabaña, tres niños enterrados y cerámicas neolíticas y campaniformes en contextos del II milenio AC (Sánchez-Polo y Blanco-González 2014). La mayoría de los 14 hoyos estudiados (Tab. 2) parecen 'efectos' de prácticas sociales (Fig. 3A2, cf. Tab. 1): se rellenaron con cerámicas recientemente rotas $(72 \%)$ y de pequeño tamaño (47\%). Otros contextos esporádicos parecen 'productos' intencionales que conservan asociaciones significativas (Fig. 3A1). Destaca la estructura 29 (Sánchez-Polo y BlancoGonzález 2014: 11-12), un rebaje alargado colmatado con detritos del II milenio AC, en cuya capa más superficial (UE 2901) se encontraron una jarrita en miniatura (¿un juguete?) y un escondrijo de 15 fragmentos de una misma olla acanalada del Neolítico Antiguo (cf. Rojo et al. 2008: 148-155) con lañados (Fig. 8A). A 15 m de allí se documentó una cabaña (estructura 23) y el hoyo 10 con tres individuos infantiles; su datación por radiocarbono $(A M S)$ y el análisis de $\mathrm{ADN}$ antiguo confirman la inhumación simultánea de tres hermanos (Esparza et al. 2012a: 280 y 307; Sánchez-Polo y Blanco-González 2014: 7-9). Una hipótesis sugerente es que parte de lo encontrado en El Cerro fuera la respuesta improvisada por aquel pequeño grupo familiar ante un episodio inesperado y de fuerte impacto emocional. La muerte pudo desencadenar el abandono del lugar (LaMotta y Schiffer 1999: 22-24), implicando la deposición de reliquias ancestrales (Lillios 1999): porciones de campaniformes y una vasija neolí-

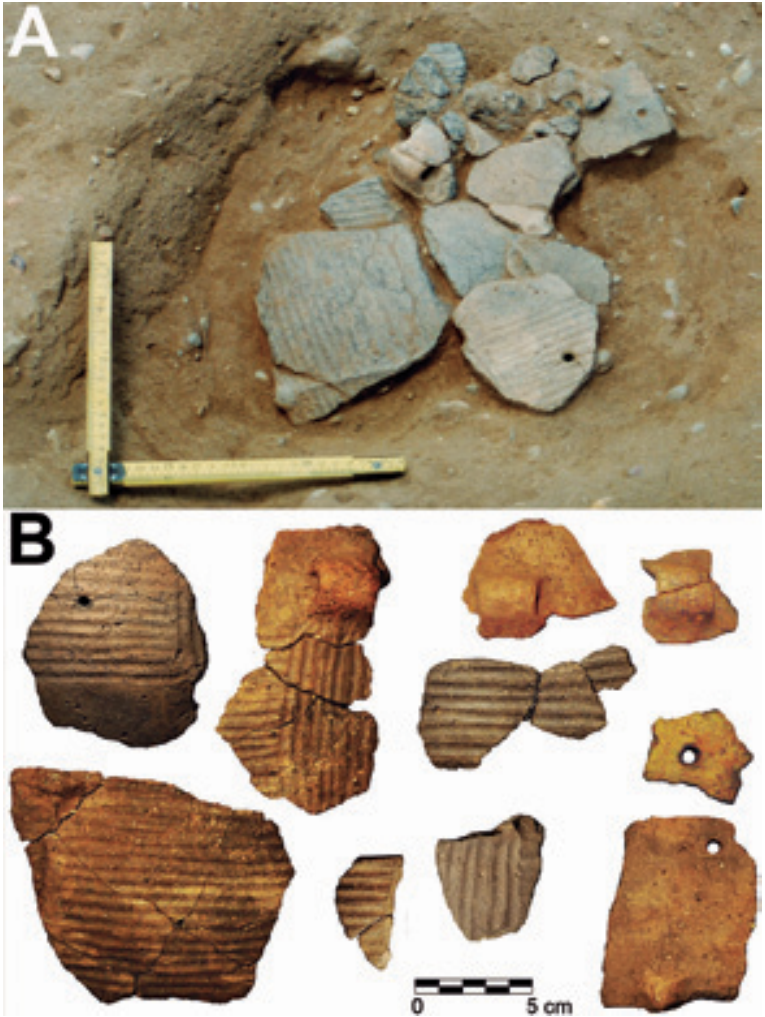

Fig. 8. El Cerro (Burgos), Bronce Medio. A. Hallazgo de fragmentos neolíticos en la estructura 29 (foto Á. L. Palomino). B. Fragmentos en perfecto estado, con lañados (foto A. Sánchez).

tica, posiblemente extraída de un contexto 3000 años más antiguo y guardada, incluso reparada (Fig. 8B), hasta su abandono definitivo.

Pico Castro (Palencia) (Fig. 2, $\mathrm{n}^{\mathrm{o}} 3$ ) es una lengua de páramo, un típico lugar encaramado de la fase final de Cogotas I (1450-1150 cal AC). Se caracterizó la cerámica $(n=1410)$ de 23 hoyos documentados en 2005 en los sectores IV y V de su cumbre (Tab. 2) (Blanco-González 2014b: 315, Fig. 7). El predominio de fragmentos huérfanos $(81 \%)$ indica que lo encontrado en las fosas es un subconjunto muy disminuido del repertorio original, bien filtrado naturalmente o seleccionado (intencional o despreocupadamente) por los ocupantes del cerro. Las proporciones de pedazos incorporados a las fosas poco después de romperse $(66 \%)$ o ya algo rodados $(29 \%)$, sugieren varias trayectorias deposicionales. Fragmentos concertantes del mismo hoyo presentan afecciones muy distintas (Fig. 9); ello indica cierto lapso temporal 


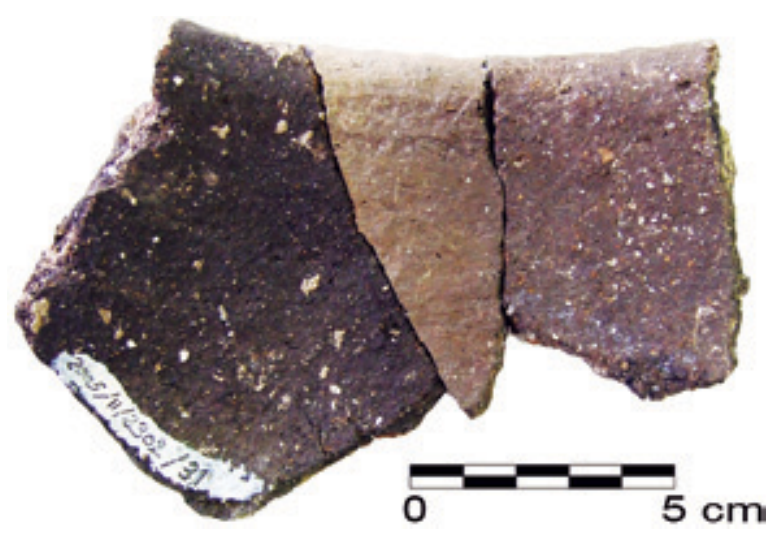

Fig. 9. Pico Castro (Palencia), Bronce Final. Tres fragmentos del mismo recipiente con aspectos muy distintos (foto A. Blanco).

y la exposición, reuso o trasiego de piezas rotas antes de ser definitivamente reunidas. Los valores obtenidos en ambos sectores presentan peculiaridades que indican dinámicas independientes, coherentes con la hipótesis de un lugar de reunión revisitado ocasionalmente durante siglos. De nuevo, la mayoría de las fosas se rellenaron con desperdicios del procesado y consumo alimenticio. También se reconocen 'productos' con diverso grado de orden e intencionalidad: desde arrojar porciones de una jarra incompleta dentro del mismo hoyo (Fig. 10); hasta colocar cosas cuidadosamente, como el conjunto cerámico del hoyo 23 (Blanco-González 2014b: 318-320, Fig. 8).
Nuevas líneas de trabajo están avanzando en una caracterización más detallada de lo que sobrevivió de Cogotas I, permitiendo comprender mejor ciertos gestos, algunos identificados hace tiempo. Es el caso de la rotura deliberada de cacharros de Cogotas I (Barroso et al. 2014: 128). Así, en la fosa de enterramiento triple de La Requejada (Fig. 1, $\mathrm{n}^{\mathrm{o}}$ 2) la mitad de un recipiente fue arrojado al pozo, mientras que la porción restante ha desaparecido. Tal comportamiento se ha relacionado (Esparza et al. 2012a: 309) con el encadenamiento simbólico (Chapman y Gaydarska 2007) entre los muertos y los vivos. Algunas de tales singularidades podrían hallar acomodo entre una racionalidad de tipo animista y una actitud apegada a los ancestros (Blanco-González 2015). Esta mentalidad habría comportado la manipulación habitual y el inusual depósito de sustancias o restos parciales de los antepasados (Esparza et al. 2012a: 274 y 277; Barroso et al. 2014: 126), entre los cuales se contarían algunas vasijas cerámicas.

\section{DISCUSIÓN}

Las grandes narrativas disponibles no consideran adecuadamente cómo ha llegado hasta nosotros lo encontrado o los inconvenientes de pensar el pasado según nuestro marco cultural. Tras tres décadas de investigación sistemática y moderna en la Península Ibérica hay contextos abundantes

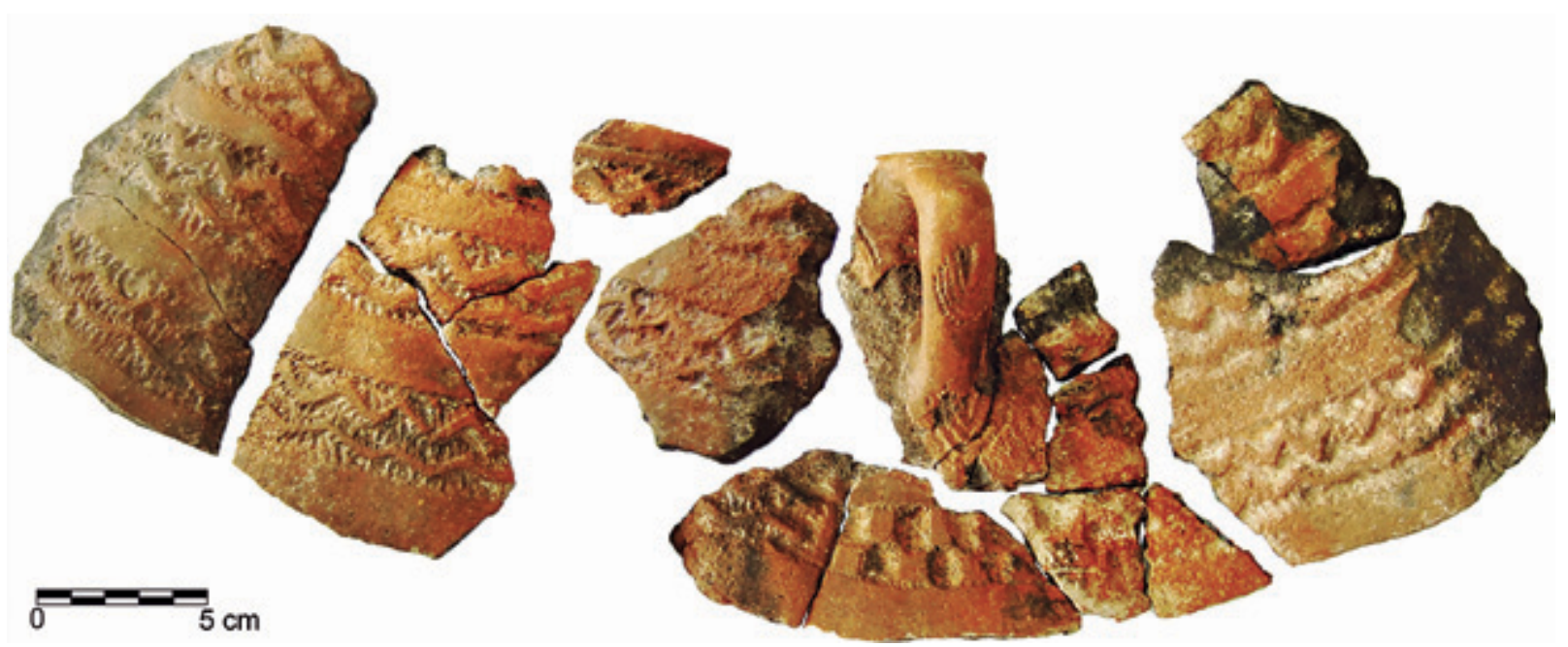

Fig. 10. Pico Castro (Palencia), Bronce Final. Fragmentos de una jarra excisa del hoyo X (foto A. Blanco).

Trab. Prehist., 73, N. ${ }^{\circ}$ 1, enero-junio 2016, pp. 47-67, ISSN: 0082-5638

doi: $10.3989 /$ tp.2016.12163 
y elocuentes y lagunas que no pueden explicarse sólo por sesgos de destrucción/ocultación o insuficiencias del trabajo de campo. Convendría abordar tal gama de escenarios con mayor equidad y distancia crítica. El Neolítico aún conserva entre nosotros algo de su alteridad, pero durante el Calcolítico el aumento cuantitativo (más sitios, mayor acumulación de desechos) y cualitativo (contextos domésticos y mortuorios variados y mejor conservados) nos lleva a considerar unánimemente una realidad demasiado obvia y familiar: cabañas y talleres reflejarían las condiciones materiales de la vida, y las sepulturas con sus ajuares transmitirían las creencias y organización social del pasado (cf. Thomas 2000: 657-658). Sherlock Holmes nos recuerda que "no hay nada más engañoso que un hecho evidente" (Doyle 2007: 487). Lo hallado es una fracción ínfima de lo que existió y necesitamos comprender mejor cómo llegó a convertirse en lo que es; no hay cabida para actitudes injustificadamente confiadas e indulgentes. Si los métodos convencionales no permiten confrontar nuestras premisas de partida y apenas adquirimos conocimiento sustantivo, es hora de cambiar las preguntas (Robb 2007: 36).

En la senda de líneas ya consolidadas de investigación tafonómica con material óseo (WeissKrejci 2012; Liesau et al. 2014a), este artículo ha explorado lo que podemos aprender al respecto observando la cerámica. En el punto de partida de esta investigación, los ciclos formativos (Jiménez Jáimez 2008) de la Prehistoria Reciente meseteña eran una realidad opaca. Para comenzar a disiparla se siguió un procedimiento inductivo e idiográfico basado en un estudio de caso múltiple, que permitiera alcanzar observaciones rigurosas y replicar los resultados (Yin 2003: 46-48).

El análisis tafonómico muestra que la mayoría de los contextos evaluados serían correlatos de prácticas sociales (Fig. 3A). Los 'efectos' o material culture patterning (Garrow 2012: 109113) ocurridos de perseguir otros fines son los casos más frecuentes aquí (Fig. 3A2). Del cierre de fosas o estructuras con sedimentos homogéneos y material abundante con frecuentes remontajes podemos afirmar su clausura antrópica relativamente rápida. Algunos están promediados temporalmente; la relación entre la formación de la matriz sedimentaria y la longevidad de los residuos incorporados a ella es arbitraria (Lucas 2012: 108-109), como el relleno de ciertas fosas de La Lámpara, El Cerro y Pico Castro o el túmulo de Los Tiesos I (Tab. 2). En otros casos el uso, rotura y abandono de vasijas fueron episodios vinculados por quienes participaron en ellos. Esto pudo ocurrir en el tramo de foso ('cabaña 013') de El Ventorro, posiblemente en el intervalo de una o dos generaciones ( $<40$ años), o en la auténtica cabaña de Fuente Lirio con una menor duración ( $<10$ años) (Tab. 2). La correspondencia con escenarios ideales (Fig. 1) no es importante; de hecho, tales arquetipos reproducen el problema de la 'equifinalidad' o posible generación de resultados similares mediante dinámicas muy distintas. Los casos estudiados muestran una enmarañada combinación de tales mecanismos. Lo crucial es considerarlos resultados no planificados, ocurridos de la repetición de hábitos corrientes: manipulación, trasiego, reutilización casual y vertido minoritario de desperdicios (Fig. 3A2). Tales tareas consuetudinarias muy posiblemente se encauzaron mediante preceptos y tabúes sobre cómo debían hacerse, normas que no inhibieron (¿ocasionalmente incluso favorecieron?) el empleo oportunista y a menudo inadvertido de restos de actividades previas. Su correlato material (Fig. 3) son agregados de residuos muy disminuidos y desplazados de su último contexto funcional (Díaz-del-Río 2001: 118-125; Gamble 2002: 108-109; Lucas 2012: 102-103; Suárez Padilla y Márquez Romero 2014: 219-220). Nos enfrentamos a palimpsestos de material redepositado (en posición secundaria o terciaria), fruto de dinámicas antropogénicas y naturales acumulativas. Tomar conciencia de ello conlleva considerar tales contextos deposicionales como muy problemáticos para recrear unas actividades prehistóricas gravemente desfiguradas.

Así pues, fueron las rutinas de la cotidianeidad prehistórica, reproducidas despreocupadamente ( decisivamente a generar la fracción conservada. A pesar de ello, tales episodios han sido relegados a un segundo plano por ciertas lecturas sociales 'de arriba abajo' (Gamble 2002; Ginzburg 2013: 217-221). A menudo se prescinde del contenido de las fosas ('basura caótica') para fijarse en las dimensiones o localización del continente (hoyo o superficie interfacial en sí). Al proceder así se minusvalora la capacidad informativa de los rellenos como 'efectos' de la acción social (Criado Boado 2012: 271) y se suplanta con esquemas abstractos (sistemas de almacenaje de excedente) 
referidos a un supuesto uso primigenio (silos) frecuentemente inverificable (Nocete 2001). Frente a tal opción, es necesario exprimir al máximo la parca información disponible, desde planteamientos más flexibles e inclusivos de cuantas líneas de trabajo sean posibles. Así, desde enfoques generalistas y deductivos hay excelentes contribuciones que integran el relleno de los hoyos en sus interpretaciones (Díaz-del-Río y Vicent 2006).

Por otra parte, era crucial suplementar la imagen proporcionada por los 'efectos' de prácticas habituales (Fig. 3A2) con aquella de los 'productos' o correlatos físicos previstos (Fig. 3A1). Entre ellos cabe reconocer contextos normales y casos divergentes de la media: serían episodios anómalos o discrepantes, testimonios genuinos de la capacidad de actuación contingente (agency) (Robb 2007; Aranda et al. 2015: xxiii). Los ejemplos extremos o estridentes han sido a menudo objeto de estudios de caso únicos (Yin 2003: 47), pero aquí era crucial confrontarlos con ejemplos normales e impersonales para poner a prueba y matizar o desechar lo que creemos conocer (Montón-Subías 2010). Además, tales episodios límite de la vida social ofrecen información resolutiva sistemáticamente ignorada por las lecturas sociales 'desde arriba' (Fig. 1), al difuminarse entre las grandes tendencias y los procesos generales. Se trata de lo 'excepcional normal' que tan buenos resultados ha procurado a la microhistoria (Ginzburg 2001; Magnússon y Szijártó 2013).

Así pues, los 'productos' son fruto de una amplia gama de prácticas sociales (Criado Boado 2012: 271-275), entre las que estarían las funerarias y votivas (Delibes 2000-2001; Rojo et al. 2005; Bueno et al. 2012b), pero también las mortuorias y otras extravagancias que apenas comprendemos. La rotura, dispersión, recuperación, manejo y deposición final de cerámica y otras sustancias fueron algunas de tales prácticas sociales transculturales. Los contextos resultantes, menos frecuentes que los 'efectos', se detectan arqueológicamente por regularidades en el orden, coherencia o completitud de los elementos que los integran. Frente al agregado aleatorio de los 'efectos' (Fig. 3A2), los 'productos' (Fig. 3A1) transmiten alguna asociación espacial significativa (Lucas 2012: 89): el hoyo 1 de La Lámpara, el escondrijo de cerámicas anacrónicas en la estructura 29 de El Cerro o el hoyo 23 de Pico Castro. El análisis no ha contemplado ningún contexto resultante de pérdidas o accidentes ocurridos en el transcurso de la vida social (Criado Boado 2012: 271, n. 323) (Fig. 3B). Tal supuesto no puede descartarse, y comienza a ser más frecuente a partir del Hierro Inicial.

Todos los resultados de prácticas sociales, tanto 'productos' como 'efectos' (Fig. 3A), ocurrieron de dedicar esfuerzo (manipular tal cosa de tal forma) para alcanzar unos fines circunstanciales e irrecuperables, pues somos incapaces de reconstruir su subjetividad original (Criado Boado 2012: 204-214). Tampoco responderían a nuestras categorías estereotipadas de instrumentalidad y causalidad moderno-occidentales (Brück 1999: 320-322). Pudieran entenderse mejor como correlato físico de una inabarcable gama de motivaciones coyunturales y polisémicas (Suárez $\mathrm{Pa}$ dilla y Márquez Romero 2014: 220). En última instancia, esos hábitos constituyeron medios clave para la reproducción social a través de su continua reelaboración (Jones 2012: 22-28 y 127). Al actuar de determinada manera para lograr algo más, lo crucial pudo ser la recreación reglada de unos preceptos (leyendas, moralejas ${ }^{4}$, relatos cosmogónicos, etc.) en episodios comunitarios de interacción social. El resultado imperecedero sería algo secundario; en ocasiones dio lugar a contextos que comparten regularidades obvias (como Valdeprados y La Calzadilla) pero las similitudes suelen ser más laxas. A veces incluso pudo haberse improvisado ante eventos inesperados, como en El Cerro. Esos propósitos últimos no eran fijos y fueron cambiando con el tiempo. Por ejemplo, para la rotura deliberada de vasijas cerámicas se han sugerido distintas lógicas singulares: deformar el jarro de La Lámpara para realzar su antropomorfismo (Rojo et al. 2008: 378); eliminar la memoria de una facción contraria en Humanejos (Flores-Fernández y Garrido-Pena 2014: 166); hacer una ofrenda votiva como agradecimiento y compensación por el beneficio de la sal en Molino Sanchón II (Abarquero et al. 2012: 332); clausurar una ceremonia en La Calzadilla (Liesau et al. 2014a: 95) o encadenar a los muertos y los vivos en La Requejada (Esparza et al. 2012: 309).

\footnotetext{
${ }^{4}$ En los casos de 'mala muerte' por defunciones reprobables (transgresores de las normas, criminales, suicidas) (Esparza et al. 2012b: 116-117, Fig. 12), la ceremonia grupal serviría como aleccionamiento.
} 
Parece sensato extremar las cautelas y no extrapolar nuestros esquemas de racionalidad. La manipulación de restos parciales resulta paradigmática: fue una tradición exitosa a lo largo de la Prehistoria Reciente, que implicó diversas sustancias y desafía categorías rígidas y dicotómicas. Para comprenderla mejor conviene aparcar nuestro antropocentrismo y reconocer el mero carácter accesorio de los huesos humanos en determinados contextos (Márquez Romero 2004: 126 y 134; Márquez Romero y Jiménez Jáimez 2014: 152153). Así, desde el Neolítico se constata la manipulación (descarnado, quemado) y desorden de restos humanos sueltos en cuevas (Weiss-Krejci 2012: 129-130) y sepulcros de corredor (Delibes 1995). Todo ello se ha venido explicando en clave funeraria: como sepulturas y ajuares alterados por diversos avatares. Pero se precisan estudios tafonómicos que nos ayuden a distinguir si efectivamente fue así, o si cámaras megalíticas y osarios hipogeos no pudieron ser lugares de interacción con los ancestros, implicando prácticas mortuorias (Thomas 2000: 655-656; Guerra et al. 2009: 48; Garrido Pena et al. 2012a: 164; Weiss-Krejci 2012: 129-130).

Aquí se ha señalado la muy posible manipulación selectiva de porciones cerámicas ya desde mediados del VI milenio AC y cómo tales gestos contribuyeron a la fracción conservada. Durante el Calcolítico parece obvio el uso fúnebre de monumentos, es decir, el tratamiento escatológico de difuntos recientes y su acompañamiento con ajuares y objetos personalizados (Rojo et al. 2005; Guerra et al. 2009; Bueno et al. 2012b). Pero casos discrepantes como los aquí revisados pudieran matizar lecturas tan uniformes y cercanas a nuestra cultura: las sepulturas pudieron ser sólo un aspecto minoritario, aunque arqueológicamente muy visible, dentro de prácticas mortuorias (de manipulación de cadáveres) más generalizadas. Porciones esqueléticas bien reconocibles (cráneos y huesos largos) son ahora objeto de ciclos de recuperación, manipulación y exhibición como reliquias ancestrales (Liesau et al. 2014c: 141147). Incluso se manejaron reliquias de animales, como un cráneo de uro muy meteorizado de La Calzadilla (Liesau et al. 2014b: 92-94). En Valdeprados, El Ventorro y varios túmulos se ha confirmado que porciones de vasijas campaniformes sufrieron un trasiego comparable al de los huesos. Así pues, los recipientes campaniformes y otros elementos del ajuar normativo (metales, sustancias exóticas) pudieron ser cosas valoradas por sus cualidades intrínsecas (pericia de ejecución, rareza, origen lejano), pero sobre todo por connotaciones extrínsecas y mutables (biografías, asociaciones a otros seres o lugares), adquiridas $\mathrm{y}$ en ocasiones perdidas. Su asociación fúnebre o mortuoria a personas concretas pudo referirse a esos significados contextuales, y no sólo a la posición social (relevancia en vida) de los finados (Brück y Fontijn 2013), auténtico tópico en la arqueología ibérica. Por último, en la Edad del Bronce la costumbre atávica de manipular restos fragmentarios resulta más perceptible (Barroso et al. 2014: 126), representando casi el 40\% de los individuos estudiados en la Submeseta Norte (Esparza et al. 2012a: 284-285). Tales prácticas, posiblemente mortuorias, se integraron en el ritual funerario normativo bajo determinadas condiciones (Esparza et al. 2012a: 284-285). Así, ciertos restos esqueléticos de óbitos corrientes, y por tanto expuestos al aire libre, habrían sido recuperados para acompañar en los hoyos a muertos recientes en circunstancias inusuales (Esparza et al. 2012b: 114-120). En conjunto, el tratamiento de cerámicas, animales y cuerpos humanos sugiere que tales grupos no distinguieron netamente entre seres animados e inertes, ni entre personas, animales y objetos (Blanco-González 2015).

\section{CONCLUSIONES}

El registro material del centro y norte ibéricos, muy incompleto y elusivo como el de otras prehistorias no convencionales (p.e. Robb 2007) obliga a extraer el máximo de información posible. Su parquedad permite observar, con las herramientas adecuadas, fenómenos desvanecidos en otras regiones por el exceso de documentación (Criado Boado 2012: 317-318). La desigual huella humana en el intervalo temporal estudiado contribuye a desmentir el supuesto empirista de que toda la vida social quedó uniformemente reflejada en el registro arqueológico (Blanco-González 2015).

El planteamiento aquí defendido sirve para iluminar cuestiones básicas desatendidas. El análisis se ha sustentado en un estudio de caso múltiple (Yin 2003) abarcando unos 10.800 fragmentos cerámicos, siguiendo un procedimiento que ha 
permitido evaluar exhaustivamente una serie de variables tafonómicas en apariencia irrelevantes, exploradas en términos del paradigma indiciario como síntomas relacionados con los avatares terminales de ocho yacimientos. Su lectura diacrónica y comparativa permite comprender mejor ciertas prácticas sociales (rotura, acopio, reuso, conservación y deposición de porciones, etc.) responsables de las huellas reconocidas en las cerámicas. Si bien la muestra ha abarcado desigualmente la variabilidad documentada en los yacimientos prehistóricos meseteños, sus principales tipos de contextos deposicionales han quedado representados. Entre las acumulaciones de desechos encuestadas es posible diferenciar dos tipos de ciclos formativos antropogénicos: a) aquellos mayoritarios y muy heterogéneos que resultaron de manipular desperdicios de manera inconsciente (aquí denominados 'efectos'); y b) algunos pocos casos de ocultaciones conscientes ('productos'), cuyos patrones de afección cerámica son mucho más restrictivos y fácilmente reconocibles. Entre los primeros, tanto las fosas, como los túmulos, o el relleno de fosos y otras estructuras afines parecen el resultado de múltiples combinaciones de procesos de reducción y dispersión de restos; sólo el caso de la cabaña de Fuente Lirio muestra un patrón marcadamente distinto.

La cerámica ha demostrado su enorme potencial como material idóneo para análisis cruzados: tanto transculturales, como integrando transversalmente documentación heterogénea recuperada con diversas estrategias de campo. Los resultados presentados son fácilmente verificables, y el método ensayado podrá aplicarse en el futuro a las toneladas de cerámica (mucha sin estudiar) que tras la 'burbuja constructiva' aguardan en los museos ibéricos, para replicar o desmentir las interpretaciones aquí esbozadas.

La interpretación ha recreado una historia social 'desde abajo' (Gamble 2002; Montón-Subías 2010), que a través de "documentos fragmentarios y deformantes" (Ginzburg 2001: 22) trata de integrar en el análisis histórico las frecuentes rutinas de manipulación y descarte de desechos cerámicos anodinos y otros episodios deliberados más excepcionales. Dichas prácticas culturales, desdeñadas por la investigación tradicional, tuvieron tanta vigencia temporal y extensión geográfica como las abstracciones que protagonizan los macrorrelatos generalistas: la neolitización, el megalitismo, el campaniforme, etc. El nivel 'micro' permite pues calibrar localmente esas grandes narrativas, aportando una necesaria apoyatura en los retazos de vida social rastreables en el registro material (Montón-Subías 2014: 549; Robb 2007). Las conclusiones de ambos enfoques, el deductivo-generalista y el inductivo-particularista, no son intercambiables ni sirven para desmentirse, pues "tienen estatutos empíricos diferentes, niveles de existencia totalmente distintos" (Criado Boado 2012: 294-295). Ya que ninguna aproximación científica puede pretender monopolizar la verdad sobre el pasado (Chalmers 1997: 203-221; Lucas 2012: 171-178), ambos modelos de conocimiento tienen un importante papel que desempeñar. Este proyecto ha aspirado a contribuir al avance disciplinar entrelazando estrategias flexibles y complementarias que, operando a diversas escalas (Robb y Pauketat 2013; Willey y Chapman 2015), ayuden a dinamizar la imaginación arqueológica (Gamble 2002: 188-190).

\section{AGRADECIMIENTOS}

Trabajo realizado en el marco del proyecto Past Fragments (FP7-PEOPLE-2011-IEF-298285) de la Comisión Europea y del contrato posdoctoral FPDI-2013-17394 financiado por el MINECO. Agradezco al personal de los museos donde estudié el material sus facilidades. J. E. Márquez Romero y dos evaluadores anónimos han contribuido a mejorar el manuscrito.

\section{BIBLIOGRAFÍA}

Abarquero, F. J.; Guerra, E.; Delibes, G.; Palomino, A. L. y Val J. M. del 2012: Arqueología de la Sal en las Lagunas de Villafáfila (Zamora): Investigaciones sobre los cocederos prehistóricos. Junta de Castilla y León. Valladolid.

Aranda, G.; Montón-Subías, S.; Sánchez-Moreno, M. 2015: The Archaeology of Bronze Age Iberia. Argaric Societies. Routledge. New York.

Arnold, P. J. III 2000: "Working without a net: recent trends in ceramic ethonoarchaeology". Journal of Archaeological Research 8 (2): 105-133.

Balsera, V.; Bernabeu Aubán, J.; Costa-Caramé, M.; Díaz-del-Río, P.; García Sanjuán, L. y Pardo, S.

Trab. Prehist., 73, N. ${ }^{\circ}$ 1, enero-junio 2016, pp. 47-67, ISSN: 0082-5638

doi: $10.3989 /$ tp.2016.12163 
2015: "The Radiocarbon Chronology of Southern Spain's Late Prehistory (5600-1000 Cal BC): a Comparative Review". Oxford Journal of Archaeology 34 (2): 139-156.

Barroso, R.; Bueno, P.; González, A.; Candelas, N.; Rojas, J. M. y López Sáez, J. A. 2014: "Enterramientos de la Edad del Bronce en la Meseta Sur peninsular a partir del Sector 22, Yuncos (Toledo)". Munibe. Antropologia-Arkeologia 65: 117-136.

Blanco-González, A. 2014a: “¿Rutinas caseras o fiestas comunitarias? Tafonomía y remontaje de la cerámica calcolítica de El Ventorro (Madrid)". Complutum 25 (1): 89-108.

Blanco-González, A. 2014b: "Sitios en altura y vasijas rotas: reconsiderando la etapa de 'plenitud' de Cogotas I (1450-1150 cal AC) en la Meseta”. Trabajos de Prehistoria 71 (2): 305-329.

Blanco-González, A. 2015: "Unconventional prehistoric worlds: untangling the Later Bronze Age in Central Iberia". Cambridge Archaeological Journal 25 (2): 435-460.

Blanco-González, A.; Kreiter, A.; Badreshany, K.; Chapman, J. y Páncél, P. 2014: "Matching sherds to vessels through ceramic petrography: an Early Neolithic Iberian case study". Journal of Archaeological Science 50: 139-152.

Brück, J. 1999: "Ritual and rationality. Some problems of interpretation in European archaeology". European Journal of Archaeology, 2 (3): 313-344.

Brück, J. y Fontijn, D. R. 2013: "The myth of the chief: prestige goods, power and personhood in the European Bronze Age". En H. Fokkens y A. Harding (eds.): The Oxford Handbook of European Bronze Age. Oxford University Press. Oxford: 197-215.

Brudenell, M. y Cooper, A. 2008: "Post-middenism. Depositional histories on Later Bronze Age settlements at Broom, Bedfordshire". Oxford Journal of Archaeology 27 (1): 15-36.

Bueno, P.; Barroso, R. y Balbín, R. de 2012a: "Meseta Sur". En M. A. Rojo, R. Garrido e I. García (eds.): El Neolítico en la Península Ibérica y su contexto europeo. Cátedra. Madrid: 507-542.

Bueno, P.; Barroso, R. y Balbín, R. de 2012b: 5.000 años atrás. Primeros agricultores y metalúrgicos del Valle de Huecas (Huecas, Toledo). Universidad de Alcalá. Madrid.

Butzer, K. W. 2007: Arqueología, una ecología del hombre. Método y teoría para un enfoque contextual. Bellaterra. Barcelona.

Cameron, C. M. y Tomka, S. A. (eds.) (1993): Abandonment of settlements and regions: ethnoarchaeological and archaeological approaches. Cambridge University Press. Cambridge.

Colomer, L.; González Marcén, P. y Montón Subías, S. 1998: "Maintenance Activities, Technological Knowledge and Consumption Patterns: A View of Northeast Iberia (2000-500 Cal BC)". Journal of Mediterranean Archaeology 11 (1): 53-80.
Contreras Cortés, F. (ed.) 2000: Proyecto Peñalosa: análisis histórico de las comunidades de la Edad del Bronce del piedemonte meridional de Sierra Morena y depresión de Linares-Bailén. Consejería de Cultura. Sevilla.

Chalmers, A. F. 1997: ¿Qué es esa cosa llamada ciencia? Siglo XXI. Madrid.

Chapman, J. y Gaydarska, B. 2007: Parts and Wholes. Fragmentation in Prehistoric Context. Oxbow. Oxford.

Criado Boado, F. 2012: Arqueológicas. La razón perdida. La construcción de la inteligencia arqueológica. Bellaterra. Barcelona.

Delibes, G. 1995: "Ritos funerarios, demografía y estructura social entre las comunidades neolíticas de la Submeseta Norte". En R. Fábregas, F. Pérez y C. Fernández (eds.): Arqueoloxía da Morte na Península Ibérica desde as Orixes ata o Medievo. Arqueohistória Limia. Xinzo de Limia: 63-125.

Delibes, G. 2000-2001: "Del Bronce al Hierro en el valle medio del Duero: una valoración del límite Cogotas I-Soto de Medinilla a partir de las manifestaciones de culto". Zephyrus LIII-LIV: 293-309.

Díaz-del-Río, P. 2001: La formación del paisaje agrario. Madrid en el III y II milenios BC. Comunidad de Madrid. Madrid.

Díaz-del-Río, P. y Vicent García, J. M. 2006: “Movilidad, funcionalidad y usos del suelo en la Prehistoria Reciente". Arqueología Espacial 26: 21-36.

Doyle, A. C. 2007: The Complete Stories of Sherlock Holmes. Wordsworth. London. $1^{\text {a }}$ ed. 1891.

Esparza, A.; Velasco, J. y Delibes, G. 2012a: "HUM 2005-00139: Planteamiento y primeros resultados de un proyecto de investigación sobre la muerte en Cogotas I'. En J. A. Rodríguez Marcos y J. Fernández Manzano (eds.): Cogotas I, una cultura de la Edad del Bronce en la Península Ibérica. Universidad de Valladolid. Valladolid: 159-320.

Esparza, A.; Velasco, J. y Delibes, G. 2012b: "Exposición de cadáveres en el yacimiento de Tordillos (Aldeaseca de la Frontera, Salamanca). Perspectiva bioarqueológica y posibles implicaciones para el estudio del ritual funerario de Cogotas I". Zephyrus LXIX (1): 95-128.

Fabián, F. 2006: El IV y III Milenios AC en el Valle Amblés (Ávila). Junta de Castilla y León. Salamanca.

Fernández-Posse, M. D. 1998. La investigación protohistórica en la Meseta y Galicia. Síntesis. Madrid.

Flores-Fernández, R. y Garrido-Pena, R. 2014: “Campaniforme y conflicto social: evidencias del yacimiento de Humanejos (Parla, Madrid)". En Actas de las Novenas Jornadas de Patrimonio Arqueológico en la Comunidad de Madrid (Museo Arqueológico Regional 2012): 159-167. Madrid.

Gamble, C. 2002: Arqueología básica. Ariel. Barcelona.

Garrido Pena, R. y Muñoz, K. 2000: "Visiones sagradas para los líderes. Cerámicas campaniformes 
con decoración simbólica en la Península Ibérica". Complutum 11: 285-300.

Garrido Pena, R.; Rojo M. A.; García, I. y Tejedor, C. 2011: "Drinking and Eating Together: The Social and Symbolic Context of Commensality Rituals in the Bell Beakers of the Interior of Iberia (2500-2000 cal BC)". En G. Aranda, S. Montón y M. Sánchez (eds.): Guess Who's Coming to Dinner. Feasting Rituals in the Prehistoric Societies of Europe and the Near East. Oxbow. Oxford: 109-129.

Garrido Pena, R.; Rojo M.A.; García, I. y Tejedor, C. 2012a: "Las máscaras de la muerte: los ritos funerarios en el Neolítico de la Península Ibérica Madrid". En M. A. Rojo, R. Garrido e I. García (eds.): El Neolítico en la Península Ibérica y su contexto europeo. Cátedra. Madrid: 143-171.

Garrido Pena, R.; Rojo M. A.; García, I. y Tejedor, C. 2012b: "Cuenca del Duero". En M. A. Rojo, R. Garrido e I. García (eds.): El Neolítico en la Península Ibérica y su contexto europeo. Cátedra. Madrid: 463-506.

Garrow, D. 2012: "Odd deposits and average practice: a critical history of the concept of structured deposition”. Archaeological Dialogues 19 (2): 85-115.

Gillham, B. 2000: Case Study Research Methods. Continuum. London y New York.

Ginzburg, C. 2001: El queso y los gusanos. El cosmos según un molinero del siglo XVI. Península. Barcelona. $1^{\text {a }}$ ed. 1976.

Ginzburg, C. 2013: Mitos, emblemas e indicios. Morfología e historia. Prometeo. Buenos Aires. 1 1 ed. 1986.

Guerra, E.; Delibes, G.; Zapatero, P. y Villalobos, R. 2009: "Primus inter pares: estrategias de diferenciación social en los sepulcros megalíticos de la Submeseta Norte española". Boletín del Seminario de Arte y Arqueología. Arqueología, LXXV: 41-65.

Hayden, B. y Cannon, A. 1983: "Where the garbage goes: refuse disposal in the Maya highlands". Journal of Anthropological Archaeology 2: 117-163.

Hernando, A. 1999: Los primeros agricultores de la Península Ibérica. Síntesis. Madrid.

Jiménez Guijarro, J. 2010: Cazadores y Campesinos. La Neolitización del Interior de la Península Ibérica. Real Academia de la Historia. Madrid.

Jiménez Jáimez, V. 2008: "El ciclo formativo del registro arqueológico. Una alternativa a la dicotomía deposicional/posdeposicional". Zephyrus 62 (2): 125-137.

Jones, A. 2012: Prehistoric Materialities. Becoming material in prehistoric Britain and Ireland. Oxford University Press. Oxford.

LaMotta, V. M. y Schiffer, M. B. 1999: "Formation Processes of House Floor Assemblages". En P. M. Allison (ed.): The Archaeology of Household Activities. Routledge. London: 19-25.

Leclerc, F. 1990: "La notion de sépulture". Bulletin et Mémories de la Société d'Anthropologie de Paris 2 (3-4): 13-18.
Liesau, C.; Esparza, A. y Sánchez, A. 2014a: “¿Huesos en la basura o depósito ritualizado? Los perros descuartizados de La Huelga (Dueñas, Palencia)”. Zephyrus 74 (2): 89-115.

Liesau, C.; Guerra, E. y Delibes, G. 2014b: "Casual or ritual: The Bell Beaker deposit of La Calzadilla (Valladolid, Spain)". Quaternary International 330: 88-96.

Liesau, C.; Ríos, P.; Vega, J.; Menduiña, R. y Blasco, C. 2014c: "Buscando los ancestros: la manipulación de los restos de las tumbas campaniforme en Camino de las Yeseras (San Fernando de Henares, Madrid)". En Actas de las Novenas Jornadas de Patrimonio Arqueológico en la Comunidad de Madrid (Museo Arqueológico Regional 2012): 137-148. Madrid.

Lillios, K. T. 1999: "Objects of Memory: The Ethnography and Archaeology of Heirlooms". Journal of Archaeological Method and Theory 6 (3): 235-262.

Lillios, K. T. 2015: "Practice, Process, and Social Change in Third Millennium BC Europe: A View from the Sizandro Valley, Portugal". European Journal of Archaeology 18 (2): 245-258.

Lucas, G. 2012: Understanding the Archaeological Record. Cambridge University Press. Cambridge.

Lull, V.; Micó, R.; Rihuete-Herrada, C. y Risch, R. 2014: "The Bronze Age in Mediterranean Iberia". En M. Almagro-Gorbea (ed.): Iberia. Protohistory of the Far West of Europe: From Neolithic to Roman Conquest. Universidad de Burgos. Burgos: 127-146.

Magnússon, S. G. y Szijártó, I. M. 2013: What Is Microhistory? Theory and Practice. Routledge. New York.

Márquez Romero, J. E. 2004: "Muerte ubicua: sobre deposiciones de esqueletos humanos en zanjas y pozos en la Prehistoria Reciente de Andalucía". Mainake XXVI: 115-138.

Márquez Romero, J. E. y Jiménez Jáimez, V. 2014. "Recent Prehistory Enclosures and Funerary Practices: some remarks". En A. C. de Valera (ed.): Recent Prehistory Enclosures and Funerary Practices in Europe. Archaeopress. Oxford: 149-154.

Maya, J. L.; Cuesta, F. y López Cachero, J. (eds.) 1998: Genó: un poblado del Bronce Final en el Bajo Segre (Lleida). Universitat de Barcelona. Barcelona.

Matthews, K. 1993: "A futile occupation? Archaeological meanings and occupation deposits". En J. W. Barber (ed.): Interpreting Stratigraphy. AOC Ltd. Edimburgo: 55-61.

Montón-Subías, S. 2010: "Black Swans and Archaeological Interpretation". Norwegian Archaeological Review 43 (1): 1-11.

Montón-Subías, S. 2014: "From the nineteenth century to the twenty-first: understanding the Bronze Age Argaric lifecourse in the Mediterranean 'far West"”. En B. Knapp y P. van Dommelen (eds.): The Cambridge Prehistory of the Bronze and Iron Age Mediterranean. Cambridge University Press. Cambridge: 540-553.

Trab. Prehist., 73, N. ${ }^{\circ}$ 1, enero-junio 2016, pp. 47-67, ISSN: 0082-5638

doi: $10.3989 /$ tp.2016.12163 
Morales, A. 1990: "Arqueozoología teórica: usos y abusos reflejados en la interpretación de las asociaciones de fauna de yacimientos antrópicos". Trabajos de Prehistoria 47: 251-290.

Nocete, F. 2001: Tercer Milenio ANE. Relaciones y Contradicciones Centro-Periferia en el Valle del Guadalquivir. Bellaterra. Barcelona.

Ortega, J. 1999: "Microespacio y microhistoria: la Arqueología del espacio doméstico". Arqueología Espacial 21: 101-116.

Priego, M. C. y Quero, S. 1992: El Ventorro, un poblado prehistórico de los albores de la metalurgia. Ayuntamiento de Madrid. Madrid.

Rídký, J.; Končelová, M.; Sumberová, R. Limburský, P. y Květina, P. 2014: "How Were Neolithic Ditches Filled In? Deposition Study of Two Enclosures from Bohemia”. European Journal of Archaeology 17 (4): 579-601.

Robb, J. 2007: The Early Mediterranean Village. Agency, Material Culture and Social Change in Neolithic Italy. Cambridge University Press. New York.

Robb, J. y Pauketat, T. R. (eds.) 2013: Big Histories, Human Lives: Tackling Problems of Scale in Archaeology. School for Advanced Research Press. Santa Fe.

Rojo, M. A.; Garrido-Pena, R.; García, I. y Tejedor, C. 2014: "Beaker barrows (not) for the dead: El Alto I \& III, Las Cuevas/El Morrón and La Perica (Soria, Spain). Cuadernos de Prehistoria y Arqueología de la Universidad Autónoma de Madrid 40: 31-40.

Rojo, M. A.; Kunst, M.; Garrido, R.; García, I. y Morán, G. 2005: Un desafio a la eternidad: Tumbas monumentales en el Valle de Ambrona. Junta de Castilla y León. Soria.

Rojo, M. A.; Kunst. M.; Garrido, R.; García, I. y Morán, G. 2008: Paisajes de la memoria: asentamientos del Neolítico antiguo en el Valle de Ambrona (Soria, España). Universidad de Valladolid. Valladolid.

Sánchez-Polo, A. y Blanco-González, A. 2014: "Death, Relics and the Demise of Huts: Patterns of Planned Abandonment in Middle BA Central Iberia (Spain)". European Journal of Archaeology 17 (1): 4-26.

Schiffer, M. B. 1985: "Is there a 'Pompeii Premise' in Archaeology?" Journal of Anthropological Research 41 (1): 18-41.

Schiffer, M. B. 1987: Formation Processes of the Archaeological Record. University of Utah Press. Salt Lake City.
Skibo, J. M. 1992: Pottery function: A use-alteration perspective. Plenum. New York.

Stake, R. E. 1995: Investigación con estudio de casos. Morata. Madrid.

Stark, M. 2003: "Current issues in ceramic ethnoarchaeology". Journal of Archaeological Research 11 (3): 193-242.

Suárez Padilla, J. y Márquez Romero, J. E. 2014: “La problemática de los fondos de cabaña en el marco de la arquitectura protohistórica del sur de la Península Ibérica”. Menga. Revista de Prehistoria de Andalucía 5: 199-225.

Thomas, J. 2000: "Death, Identity and the Body in Neolithic Britain". Journal of the Royal Anthropological Institute 6: 653-668.

VVAA 2003: Trace 43. Abandono de Asentamientos Prehispánicos. Centro de Estudios Mexicanos y Centroamericanos. México.

Waddington, K. 2014: "The Biography of a Settlement: An Analysis of Middle Iron Age Deposits and Houses at Howe, Orkney". Archaeological Journal 171: 61-96.

Walker, W. H. 1995: “Ceremonial trash?”. En J. M. Skibo, W. M. Walker y A. E. Nielsen (eds.): Expanding Archeology. University of Utah Press. Salt Lake City: 67-79.

Weiss-Krejci, E. 2012: "Shedding Light on Dark Places. Deposition of the Dead in Caves and Cave-Like Features in Neolithic and Copper Age Iberia". En K. A. Bergsvik y R. Skeates (eds.): Caves in Context. The Cultural Significance of Caves and Rockshelters in Europe. Oxbow. Oxford: 118-137.

Wolfram, S. 2013: "Two sides of the coin: ceramic taphonomy and domestic space in the Linear Pottery settlements Hanau-Klein-Auheim and Eythra (Germany)". En C. Hamon, P. Allard y M. Ilett (eds.): The Domestic Space in LBK Settlements Verlag Marie Leidorf GmbH. Rahden/Westf: 79-90.

Wylie, A. y Chapman, R. 2015: "Material evidence: learning from archaeological practice". En R. Chapman y A. Wylie (eds.): Material Evidence: Learning from Archaeological Practice. Routledge. New York: $1-20$.

Yin, R. C. 2003: Case Study Research. Design and Methods. Sage. Newbury Park CA. 